Article

\title{
Widespread Ability of Ligninolytic Fungi to Degrade Hazardous Organic Pollutants as the Basis for the Self-Purification Ability of Natural Ecosystems and for Mycoremediation Technologies
}

\author{
Natalia Pozdnyakova ${ }^{1, *}$, Ekaterina Dubrovskaya ${ }^{1}$, Dietmar Schlosser ${ }^{2} \mathbb{D}$, Svetlana Kuznetsova ${ }^{1}$, Elena Sigida ${ }^{1}$, \\ Vyacheslav Grinev ${ }^{1}$, Sergei Golubev ${ }^{1}$, Elena Kryuchkova ${ }^{1}$, Giovanna Cristina Varese ${ }^{3}{ }^{D}$ and Olga Turkovskaya ${ }^{1}$ \\ 1 Saratov Scientific Centre of the Russian Academy of Sciences (IBPPM RAS), Institute of Biochemistry and \\ Physiology of Plants and Microorganisms, Prospekt Entuziastov 13, 410049 Saratov, Russia; \\ dubrovskaya_e@ibppm.ru (E.D.); kuznetsova_s@ibppm.ru (S.K.); sigida_e@ibppm.ru (E.S.); \\ grinev_v@ibppm.ru (V.G.); golubev_s@ibppm.ru (S.G.); kryuchkova_e@ibppm.ru (E.K.); \\ turkovskaya_o@ibppm.ru (O.T.) \\ 2 Helmholtz Centre for Environmental Research-UFZ, Permoserstrasse 15, 04318 Leipzig, Germany; \\ dietmar.schlosser@ufz.de \\ 3 Department of Life Sciences and Systems Biology, University of Turin, Viale Mattioli 25, 10125 Torino, Italy; \\ cristina.varese@unito.it \\ * Correspondence: pozdnyakova_n@ibppm.ru
}

check for updates

Citation: Pozdnyakova, N.; Dubrovskaya, E.; Schlosser, D.; Kuznetsova, S.; Sigida, E.; Grinev, V.; Golubev, S.; Kryuchkova, E.; Varese, G.C.; Turkovskaya, O. Widespread Ability of Ligninolytic Fungi to Degrade Hazardous Organic Pollutants as the Basis for the Self-Purification Ability of Natural Ecosystems and for Mycoremediation Technologies. Appl. Sci. 2022, 12, 2164. https://doi.org/10.3390/ app12042164

Academic Editor: Simone Morais

Received: 9 January 2022

Accepted: 16 February 2022

Published: 18 February 2022

Publisher's Note: MDPI stays neutral with regard to jurisdictional claims in published maps and institutional affiliations.

Copyright: (C) 2022 by the authors. Licensee MDPI, Basel, Switzerland. This article is an open access article distributed under the terms and conditions of the Creative Commons Attribution (CC BY) license (https:// creativecommons.org/licenses/by/ $4.0 /)$.
Featured Application: The potential application of the results is in the field of mycoremediation of contaminated sites.

\begin{abstract}
The ability of sixteen wood- and soil-inhabiting basidiomycete strains and four ascomycete strains to degrade the most hazardous, widespread, and persistent pollutants (polycyclic aromatic hydrocarbons, oxyethylated nonylphenol, alkylphenol, anthraquinone-type synthetic dyes, and oil) was found. The disappearance of the pollutants, their main metabolites, and some adaptive properties (activities of ligninolytic enzymes, the production of emulsifying compounds and exopolysaccharides) were evaluated. The toxicity of polycyclic aromatic hydrocarbons decreased during degradation. New data were obtained regarding (1) the dependence of the completeness of polycyclic aromatic hydrocarbon degradation on the composition of the ligninolytic enzyme complex; (2) the degradation of neonol AF9-12 by higher fungi (different accessibilities of the oxyethyl chain and the aromatic ring of the molecules to different fungal genera); and (3) the production of an emulsifying agent in response to the presence in the cultivation medium of hydrophobic pollutants as the common property of wood- and soil-inhabiting basidiomycetes and ascomycetes. Promise for use in mycoremediation was shown in the wood-inhabiting basidiomycetes Pleurotus ostreatus f. Florida, Schizophyllum commune, Trametes versicolor MUT 3403, and Trametes versicolor DSM11372; the litter-decomposing basidiomycete Stropharia rugosoannulata; and the ascomycete Cladosporium herbarum. These fungi degrade a wide range of pollutants without accumulation of toxic metabolites and produce ligninolytic enzymes and emulsifying compounds.
\end{abstract}

Keywords: fungi; biodegradation; hazardous pollutants; ligninolytic enzymes; emulsifying activity; mycoremediation

\section{Introduction}

Environmental contamination by hazardous pollutants is a serious and challenging problem of the present time. The range of pollutants, which enter the environment as a result of human economic activities and natural processes, is very broad and includes several class of compounds (polycyclic aromatic hydrocarbons (PAHs), synthetic dyes, 
detergents, chlorinated compounds, pharmaceutical compounds, dioxins, plastics, etc.) and resulting mixtures (creosote, oil, etc.). The discharge and accidental entry of pollutants into the environment is a serious problem, especially when the biodegradation activity of the natural microbiota is insufficient for their removal or neutralization.

Natural ecosystems have great detoxification potential, which is ensured by the degradative activity of different organisms. These include basidio- and ascomycetes, some of the most numerous groups of the kingdom of Fungi. The ability of fungi to degrade a wide range of natural compounds and xenobiotics is an important part of the self-purification ability of ecosystems and can be used for the development of ecological biotechnologies [1].

Currently, an active search for technologies of bioremediation of contaminated soils and water is in progress. The fungal degradation or transformation of hazardous organic compounds is called mycoremediation [2-6]. This simple and relatively inexpensive biotechnology could be applied to the remediation of soil and water polluted by industrial and agricultural waste, oil, and its byproducts, and a wide range of xenobiotics) [2-6]. Fungi fulfill various functions in ecosystems and have great degradation potential; therefore, they are attractive candidates for use in mycoremediation technologies. However, detailed studies of the degradative properties of fungi and their adaptation to pollution are necessary before they are used for mycoremediation.

Ligninolytic fungi are an eco-physiological group of wood- and soil-inhabiting basidioand ascomycetes, which are uniquely able to depolymerize and mineralize lignin in nature. The following properties make these fungi attractive for use in mycoremediation: (1) the ability to decompose and mineralize a wide range of persistent aromatic compounds that are structurally similar to the compounds formed during biosynthesis or biodegradation of lignin; (2) the wide distribution in nature; (3) the ability to grow on cheap natural substrates which can easily be introduced to polluted soil; (4) growth in the form of hyphae, allowing them to reach pollutants that are inaccessible to bacteria; (5) the production of a powerful extracellular nonspecific oxidative enzyme system; (6) the presence of lowmolecular-weight mediators that may increase the susceptibility of pollutants to enzymatic attack; (7) the production of constitutive forms of ligninolytic enzymes regardless of the presence of pollutants, which prevent the adaptation of the organism to contamination conditions $[1,2,7]$.

The polymeric and hydrophobic structure of the macromolecule of lignin determines the properties of the degrading enzyme system, which is extracellular, nonspecific, and nonhydrolytic. Ligninolytic fungi produce four main groups of lignin-modifying enzymes: lignin peroxidases (EC 1.11.1.14), Mn-dependent peroxidases (Mn-peroxidases, EC 1.11.1.13), versatile peroxidases (EC 1.11.1.16), and laccases (EC 1.10.3.2) [7].

This enzymatic system allows fungi to transform and mineralize, in addition to lignin, pesticides, polychlorinated biphenyls, halogenated aromatic compounds, nitro- and aminosubstituted phenols, synthetic dyes, PAHs, etc. [7-9]. Only a few studies have reported the use of ligninolytic fungi for the mycoremediation of sites contaminated by complex mixtures of pollutants, such as creosote and oil [10-14].

Many persistent environmental pollutants are represented by hydrophobic compounds. Their bioavailability can limit the fungal attack [15]. Stimulation of their desorption from soil by various surfactants can increase their bioavailability $[16,17]$. However, some surfactants, such as Triton X-100, are very difficult to degrade; as a result, stable and toxic products form that can accumulate in the environment $[18,19]$.

Many well-known bacterial degraders are known to synthesize biosurfactants [20]. However, only a few reports have described the production of biosurfactants during the degradation of hydrophobic pollutants by ligninolytic fungi [14,21-24].

The focus of this study is the assessment of the degradative activity towards persistent pollutants (PAHs, nonionic surfactants, anthraquinone-type synthetic dyes, and oil) and of the adaptive potential of natural fungi belonging to different divisions of the kingdom Fungi (basidio- and ascomycetes) and ecological-physiological groups (wood- and soil- 
inhabiting fungi). Research on the fungal species combining the ability to degrade a wide range of environmental pollutants with the production of biosurfactants is one possible key to the explanation of the self-purification ability of contaminated ecosystems and the successful implementation of mycoremediation strategies.

\section{Materials and Methods}

\subsection{Fungi and Cultivation Conditions}

Schizophyllum commune IBPPM541, Pleurotus ostreatus f. Florida IBPPM540, Pleurotus ostreatus 336, Pleurotus ostreatus D1 (Jacquin) P. Kummer, Lecanicillum aphanocladii Zare \& W. Gams IBPPM542, and Fusarium oxysporum IBPPM543 were from the Collection of Rhizosphere Microorganisms (IBPPM RAS, Russia); Trametes hirsuta LE-BIN072, Trametes maxima LE-BIN0275, Trametes ochracea LE-BIN093, Trametes gibbosa LE-BIN1911, Lenzites betulina LE-BIN2047, Pleurotus ostreatus LE-BIN0432, and Steccherinum murashkinskyi LEBIN1963 were from the RAS Federal Research Centre "Fundamentals of Biotechnology" (Moscow, Russia); Trametes versicolor MUT3403, Pleurotus ostreatus MUT2977, Bjerkandera adusta MUT3398, Geotrichum candidum MUT4803, and Cladosporium herbarum MUT3238 were from Mycotheca Universitatis Taurinensis (Turin, Italy); Trametes versicolor DSM11269 and Stropharia rugosoannulata DSM11372 were from Helmholtz Centre for Environmental Research-UFZ (Leipzig, Germany) (Table S1).

The fungi were grown in a basidiomycetes-rich medium with our modifications $(\mathrm{g} / \mathrm{L})$ [25]: $\mathrm{NH}_{4} \mathrm{NO}_{3}, 0.724 ; \mathrm{KH}_{2} \mathrm{PO}_{4}, 1.0 ; \mathrm{MgSO}_{4} \times 7 \mathrm{H}_{2} \mathrm{O}, 1.0 ; \mathrm{KCl}, 0.5$; yeast extract, 0.5; $\mathrm{FeSO}_{4} \times 7 \mathrm{H}_{2} \mathrm{O}, 0.001 ; \mathrm{ZnSO}_{4} \times 7 \mathrm{H}_{2} \mathrm{O}, 0.0028 ; \mathrm{CaCl}_{2} \times 2 \mathrm{H}_{2} \mathrm{O}, 0.033 ; D$-glucose, 10.0; peptone, 10.0. Alternatively, the fungi were grown in Kirk's medium with our modifications (g/L) [26]: $\mathrm{KH}_{2} \mathrm{PO}_{4}, 0.2 ; \mathrm{MgSO}_{4} \times 7 \mathrm{H}_{2} \mathrm{O}, 0.05 ; \mathrm{CaCl}_{2}, 0.01$; thiamine, 0.0025; $\mathrm{NH}_{4} \mathrm{NO}_{3}, 0.724$. The $\mathrm{pH}$ of Kirk's medium was maintained with $25 \mathrm{mM}$ phosphate buffer (pH 6.0), and maltose (1\%) served as the carbon and energy source. Kirk's medium was supplemented with $0.1 \%$ Tween- 80 to increase ligninolytic enzyme production. Cultivation was performed at $24-26^{\circ} \mathrm{C}$ with shaking (130 rpm).

Pollutants were added on day 2 of growth to final concentrations of $50 \mathrm{mg} / \mathrm{L}$ for PAHs (anthracene, phenanthrene, or fluorene) and anthraquinone dyes (Acid Blue 62 and Reactive Blue), $200 \mathrm{mg} / \mathrm{L}$ for a nonionic surfactant (neonol AF9-12) and isononylphenol (isomeric mixture), and $5 \mathrm{~g} / \mathrm{L}$ for oil. PAHs and isononylphenol were added as a chloroform stock solution: $5 \mathrm{mg} / 100 \mu \mathrm{L}$ and $20 \mathrm{mg} / 200 \mu \mathrm{L}$, respectively. Control treatments contained $100 \mu \mathrm{L}$ of chloroform, which was added on day 2 of fungal growth. After 14 days, residual PAHs, neonol AF9-12, isononylphenol, and oil were extracted from the bulk of flasks (without separation of the cultivation medium and mycelia) with chloroform $(5 \mathrm{~mL}$, three times). The resulting extracts were evaporated and were analyzed as described below. The mycelium and the cultivation medium were separated by filtration. The mycelium increment ( $\mathrm{mg}$ of dry biomass) was determined by weighing.

\subsection{Chromatography}

The PAHs and their metabolites were analyzed by gas chromatography (GC) (Shimadzu 2010) with a flame photometric detector. Compounds were separated by using an HP5 column (Agilent), with helium as the carrier gas. The column temperature was kept at $200{ }^{\circ} \mathrm{C}$ for $3 \mathrm{~min}$, then programmed to increase to $270{ }^{\circ} \mathrm{C}$ at $15^{\circ} \mathrm{C} \mathrm{min}-1$, and finally kept at $270{ }^{\circ} \mathrm{C}$ for $2 \mathrm{~min}$. Before GC analysis, 2,2' -diphenic and phthalic acids were methylated with $\mathrm{CH}_{3} \mathrm{COCl}$. Commercial anthracene (RT-4.15 $\mathrm{min}$ ), 9,10-anthraquinone (RT-5.39 $\mathrm{min}$ ), phenanthrene (RT-4.08 $\mathrm{min}$ ), phenanthrene-9,10-quinone (RT-6.86 $\mathrm{min}$ ), fluorene (RT-5.57 $\mathrm{min}$ ), 9-fluorenone (RT-4.33 $\mathrm{min}$ ), 2-carboxybenzaldehyde (RT-7.31 $\mathrm{min}$ ), 2,2'-diphenic acid (RT-6.7 $\mathrm{min}$ ), and phthalic acid (RT-8.99 $\mathrm{min}$ ) were used as the marker compounds to identify the PAH oxidation products. GC analysis was carried out at the "Simbioz" Centre for the Collective Use of Research Equipment in the Field of PhysicalChemical Biology and Nanobiotechnology (Institute of Biochemistry and Physiology of 
Plants and Microorganisms, Saratov Scientific Centre of the Russian Academy of Sciences (IBPPM RAS)).

The oil disappearance was measured by adsorption chromatography with gravimetric termination. Oil was extracted three times by $5 \mathrm{~mL}$ of chloroform; the extracts were evaporated and applied to a column of $\mathrm{Al}_{2} \mathrm{O}_{3}(10 \mathrm{~mL})$. The oil was eluted by chloroform and dried to complete evaporation of the solvent and the amount of oil was determined by the gravimetric method. The changes in the fractional composition of the oil were determined by adsorption chromatography on an $\mathrm{Al}_{2} \mathrm{O}_{3}$ column, followed by polarimetric and gravimetric analysis. The paraffins $(\mathrm{Nd}=1.41-1.43)$ were eluted with $40 \mathrm{~mL}$ of hexane; naphthenes $(\mathrm{Nd}=1.45-1.49)$, with $60 \mathrm{~mL}$ of hexane; low-molecular-weight aromatic hydrocarbons $(\mathrm{Nd}=1.49-1.53), 100 \mathrm{~mL}$ of a mixture of $15 \%$ benzene in hexane; highmolecular-weight aromatic hydrocarbons ( $\mathrm{Nd}>1,59), 100 \mathrm{~mL}$ benzene; and tars (refractive index not determined), $80 \mathrm{~mL}$ of ethanol/benzene (1:1). The fractions were dried to complete evaporation of the solvent and analyzed by gravimetric method [27]. The oil used was composed as follows (\%): paraffins-51.7, naphthenes-17.0, low-molecularweight aromatic hydrocarbons-10.3, high-molecular-weight aromatic hydrocarbons-7.3, and tars-13.5.

\subsection{Spectrophotometric Analysis}

The nonionic surfactant was determined by spectrophotometric analysis with phosphomolybdic acid [28]. The degradation of the aromatic ring of neonol AF9-12 and isononylphenol was determined spectrophotometrically at $277 \mathrm{~nm}$ [29].

Owing to the optical opacity of the basidiomycetes-rich medium, decolorization of dyes was studied on Kirk's medium at 6.0. Aliquots $(2 \mathrm{~mL})$ were taken from the flasks at intervals, and the dye disappearance was tested spectrophotometrically by the change in the absorption spectra at $590 \mathrm{~nm}$ [30].

\subsection{Infrared Spectrometry}

Infrared spectra of neonol AF9-12 and isononylphenol were recorded on a Nicolet 6700 IR-Fourier spectrometer (Thermo Scientific, Waltham, MA, USA) in KBr tablets (FT-IR grade, $\geq 99 \%$, Sigma-Aldrich, St. Louis, MO, USA) in the transmission mode in the range $4000-400 \mathrm{~cm}^{-1}$. The spectral resolution was $4 \mathrm{~cm}^{-1}$, and the number of scans of the sample and the reference sample was 32 .

\subsection{Enzymatic Analysis}

Laccase activity was measured by the oxidation rate for 2,2'-azino-bis(3-ethylbenzothiazoline-6-sulfonic acid)diammonium salt (ABTS) at $436 \mathrm{~nm}\left(\varepsilon=29,300 \mathrm{M}^{-1} \mathrm{~cm}^{-1}\right)$, according to Niku-Paavola et al. [31]. Mn-peroxidase was measured by the oxidation rate for 2,6-dimethoxyphenol (DMP) with $\mathrm{H}_{2} \mathrm{O}_{2}$ and $\mathrm{Mn}^{2+}$ at $468 \mathrm{~nm}\left(\varepsilon=14,800 \mathrm{M}^{-1} \mathrm{~cm}^{-1}\right)$, according to Heinfling et al. [32]. Peroxidase activity was calculated as the difference between the values for DMP oxidation with and without $\mathrm{H}_{2} \mathrm{O}_{2}$. Lignin peroxidase was measured by the formation of the oxidation product of veratryl alcohol at $310 \mathrm{~nm}$ $\left(\varepsilon=9300 \mathrm{M}^{-1} \mathrm{~cm}^{-1}\right)$ [33]. One unit of enzyme activity $(\mathrm{U} / \mathrm{mL})$ is defined as the amount of enzyme that oxidizes $1 \mu \mathrm{M}$ of substrate per min.

\subsection{Emulsifying Activity Measurements}

The emulsifying activity of the culture medium was tested by Cooper's method [34]. The culture medium after fungal growth both with and without pollutants was mixed 2:3 with kerosene, shaken for $20 \mathrm{~min}$, and left to stand at room temperature for $48 \mathrm{~h}$. Emulsifying activity $\left(\mathrm{E}_{48}\right)$ was calculated as the ratio of emulsion volume to total liquid volume and expressed in percentage. 


\subsection{Polysaccharide Concentration Measurements}

Concentrations of free reducing sugars in sample aliquots were determined using the dinitrosalicylic acid (DNSA) method according to Bailey [35]. After acidic hydrolysis, the total sugars in sample aliquots were measured photometrically on the basis on the phenol-sulfuric acid method [36]. For both methods, calibration curves were established from equal amounts of mixed $D$-glucose and $D$-fructose. Polysaccharide concentrations were calculated as the difference between total and free reducing sugar concentrations.

\subsection{Phytotoxicity Estimation}

The test object was sorghum (Sorghum bicolor L. Moench). Seeds had been calibrated and surface-sterilized with a mixture of ethanol and hydrogen peroxide (1:1). Germinating capacity was determined as the percentage of germinated seeds relative to the total seeds tested. The tested compounds were dissolved in chloroform at a concentration of $0.25 \mathrm{mg} / \mathrm{mL} ; 1 \mathrm{~mL}$ of the solution was applied to sterile paper filters placed in sterile glass Petri dishes $10 \mathrm{~cm}$ in diameter. Filters treated with the same amount of chloroform were used as the control treatment. The phytotoxicity of PAHs and their derivatives that are potential fungal metabolites was estimated. Among these compounds, there were PAHs: phenanthrene, anthracene, and fluorene; quinones: phenanthrene-9,10-quinone and 9,10-anthraquinone; ketone 9-fluorenone; acids: 2-formylbenzoic (2-carboxybenzaldehyde), $2,2^{\prime}$-diphenic, and phthalic. On the third day after complete evaporation of the solvent, the filters were moistened with $5 \mathrm{~mL}$ of sterile water, and 20 seeds were placed on each of them. Three replicates were used for each tested compound. In 3-day-old seedlings, the length of roots and shoots was measured. Means were calculated and expressed as the percentage of the control values.

\subsection{Chemicals}

Anthracene, fluorene, phenanthrene, 2,2'-azino-bis(3-ethylbenzothiazoline-6-sulfonic acid) diammonium salt (ABTS), 2,6-dimethoxyphenol (DMP), veratryl alcohol, 2-carboxybenzaldehyde, 2,2'-diphenic and phthalic acids, Acid Blue 62, and Reactive Blue were from Fluka (Buchs, Switzerland); all the other pollutants were from Reachim Co. (Moscow, Russia).

All experiments were run in triplicate, each having been repeated at least three times. Data were statistically processed; the means were calculated and compared by the index of least significant difference at $p<0.05$ by using Fisher's exact test. Calculations were performed using Statistica software v.7 (StatSoft, Moscow, Russia) and Microsoft Excel 2003.

\section{Results and Discussion}

We used 20 strains of fungi belonging to two divisions of the kingdom of Fungi (Basidiomycota and Ascomycota): 16 strains of ligninolytic basidiomycetes (15 strains of wood-inhabiting and 1 strain of soil-inhabiting, litter-decomposing, fungi) and 4 strains of ascomycetes.

Fungi of the genera Pleurotus and Trametes, and Bjerkandera adusta are common objects of biodegradation studies $[14,24,37,38]$. In our experiments, five strains of $P$. ostreatus were used for the detection of strain-specific differences in degradative properties. Six members of genus Trametes, including two strains of T. versicolor, were used also. In this case, the differences in the degradative properties of different species of Trametes were found. Some other wood-inhabiting basidiomycetes, including Lenzites betulina, Schizophyllum commune, and Steccherinum murashkinskyi, were used. Pleurotus ostreatus f. Florida and Schizophyllum commune were isolated from creosote-contaminated railway sleeper wood and identified using a polyphasic approach, combining morphophysiological observation of the colonies with molecular tools (data not presented).

Litter-decomposing fungi are another ecophysiological group of basidiomycetes, which can cause the so-called white rot of humus. Some genera of this group are promising organisms for use in soil remediation. The agaric basidiomycetes Stropharia rugosoannulata 
and Stropharia coronilla are efficient PAH degraders, and bisphenol A [39,40]. S. rugosoannulata strain DSM11372 was used in our studies.

The participation of ascomycetes in the degradation of pollutants is known. Fusarium oxysporum is able to significantly reduce the concentration of oil and to degrade and mineralize anthracene, phenanthrene, and pyrene [41,42]. Geotrichum candidum decolorized 21 types of reactive dyes, including azo and anthraquinone dyes [43]. Among the Cladosporium species, known to degrade hydrocarbons, $C$. resinae has the name the "kerosene" or "creosote" fungus, because it occurs in aviation fuel and causes damage by clogging filters and corroding pumps and tanks. C. herbarum, isolated from polluted sites, is able to degrade PAHs in a liquid medium [44]. The degradative properties of the entomopathogenic Lecanicillium species have been poorly studied. For example, L. saksenae is an active decomposer of the pesticide pendimethalin, and V. lecanii is a decomposer of 2,4-dichlorophenol and 2,4-dichlorophenoxyacetic acid and anthracene [45-47].

On the basis of these literature data, four species of ascomycetes (C. herbarum, F. oxysporum Schltdl., G. candidum, and L. aphanocladii Zare \& W. Gams) were used in our experiments. F. oxysporum Schltdl. and L. aphanocladii Zare \& W. Gams were isolated from creosote-contaminated samples. The fungi were identified by a polyphasic approach, combining morphophysiological observation of the colonies with molecular tools. The accession numbers of the sequences deposited in GenBank are F. oxysporum-MG593980; L. aphanocladii-MG593981 [48].

\subsection{Pollutant Disappearance Experiments}

\subsubsection{Polycyclic Aromatic Hydrocarbons (PAHs)}

The considerable interest in biodegradation mechanisms and environmental fate of PAHs is due to their wide distribution, resistance to degradation, accumulation in soils and sediments, and toxic, mutagenic, and carcinogenic properties [15]. Many reviews on the biodegradation of this class of pollutant are available. The corresponding quinones (e.g., 9,10-anthraquinone, phenanthrene-9,10-quinone, and benzo[a]anthracene-7,12-quinone) are discussed as the main metabolites $[38,49]$.

The three-ring PAHs used in our experiments (phenanthrene, anthracene, and fluorene) are not mutagenic or carcinogenic to humans [15]. However, they are often used as model compounds for the study of the biodegradation of PAHs. They are found in PAH-containing samples, and many PAH derivatives are carcinogenic.

In our experiments, all fungi actively removed PAHs, as evidenced by the decrease in their concentration after 14 days of cultivation (Table 1). Previous experiments showed that PAH sorption by living fungal mats was significantly lower than that by heat-killed ones. This finding agrees with the data of Gramss and Mascher [50]. According to the data obtained, we used two consistent extraction procedures: (1) extraction from full contents of the flasks; (2) the cultivation medium was separated from mycelia, and the mycelium was extracted again. Insignificant sorption of the studied PAHs to mycelia (5-7\%) was shown.

In general, the basidiomycetes removed these compounds more actively than did the ascomycetes (Table 1). Anthracene was the least available to all fungi. The disappearance of this compound varied from 16 to $91 \%$ with the basidiomycetes. Anthracene was inaccessible to the ascomycetes F. oxysporum and G. candidum. Phenanthrene and fluorene were removed by both basidio- and ascomycetes (17.7-100 and 16.8-100\%, respectively) (Table 1).

The degradative activity towards PAHs showed both strain and species differences. Within the species Pleurotus ostreatus, the most active was P. ostreatus D1 (the disappearance of phenanthrene and fluorene reached $100 \%$ ). Within the genus Trametes, both T. versicolor and T. maxima strains were active degraders, whereas T. gibbosa was not very active.

One of the most active degraders was the ascomycete $C$. herbarum which showed a removal efficiency of about $100 \%$ with all PAHs used. The literature has a single report on the degradation of PAHs by another member of this genus, C. sphaerospermum. However, in that study, the disappearance of three-ring PAHs did not exceed 35\% [44]. 
Table 1. PAHs disappearance (\%) by the selected fungi.

\begin{tabular}{|c|c|c|c|c|}
\hline \multirow{2}{*}{ № } & \multirow{2}{*}{ Fungi } & \multicolumn{3}{|c|}{ PAH Disappearance (\%) } \\
\hline & & ANT & PHEN & FLU \\
\hline 1 & Bjerkandera adusta MUT 3398 & $61.6 \pm 3.0$ & $82.8 \pm 4.8$ & $96.2 \pm 7.2$ \\
\hline 2 & Cladosporium herbarum MUT 3238 & $94.1 \pm 1.0$ & $95.4 \pm 2.5$ & $98.0 \pm 2.4$ \\
\hline 3 & Fusarium oxysporum IBPPM 543 & $0 \pm 2.3$ & $20.8 \pm 1.2$ & $41.9 \pm 3.5$ \\
\hline 4 & Geotrichum candidum MUT4803 & $0 \pm 3.0$ & $17.7 \pm 1.3$ & $16.8 \pm 7.1$ \\
\hline 5 & Lecanicillium aphanocladii IBPPM 542 & $39.8 \pm 12.1$ & $62.8 \pm 2.8$ & $81.3 \pm 3.0$ \\
\hline 6 & Lenzites betulina LE-BIN 2047 & $89.3 \pm 8.6$ & $74.4 \pm 18.8$ & $99.2 \pm 5.7$ \\
\hline 7 & Pleurotus ostreatus f. Florida IBPPM 540 & $50.9 \pm 5.7$ & $70.8 \pm 2.1$ & $93.9 \pm 5.4$ \\
\hline 8 & Pleurotus ostreatus MUT2977 & $92.0 \pm 3.2$ & $71.2 \pm 13.7$ & $93.0 \pm 1.3$ \\
\hline 9 & Pleurotus ostreatus 336 & $56.7 \pm 1.8$ & $71.3 \pm 1.6$ & $86.6 \pm 2.9$ \\
\hline 10 & Pleurotus ostreatus D1 & $85.3 \pm 4.2$ & $100 \pm 6.8$ & $100 \pm 5.3$ \\
\hline 11 & Pleurotus ostreatus LE-BIN0432 & $36.7 \pm 11.8$ & $79.3 \pm 15.5$ & $94.8 \pm 18.9$ \\
\hline 12 & Schizophyllum commune IBPPM 541 & $49.5 \pm 2.6$ & $39.8 \pm 8.5$ & $74.2 \pm 9.4$ \\
\hline 13 & Steccherinum murashkinskyi LE-BIN 1963 & $71.8 \pm 2.6$ & $76.1 \pm 7.2$ & $91.5 \pm 6.5$ \\
\hline 14 & Stropharia rugosoannulata DSM11372 & $49.5 \pm 3.1$ & $55.2 \pm 4.9$ & $72.2 \pm 7.0$ \\
\hline 15 & Trametes gibbosa LE-BIN 1911 & $17.0 \pm 6.3$ & $45.3 \pm 7.2$ & $51.8 \pm 18.8$ \\
\hline 16 & Trametes hirsuta LE-BIN 072 & $37.8 \pm 2.6$ & $59.6 \pm 4.4$ & $90.4 \pm 2.5$ \\
\hline 17 & Trametes maxima LE-BIN 0275 & $84.6 \pm 2.1$ & $78.8 \pm 15.6$ & $95.4 \pm 22.9$ \\
\hline 18 & Trametes ochracea LE-BIN 093 & $16.2 \pm 5.6$ & $48.5 \pm 19.8$ & $85.2 \pm 22.1$ \\
\hline 19 & Trametes versicolor DSM11372 & $57.1 \pm 7.8$ & $79.8 \pm 2.7$ & $96.8 \pm 7.1$ \\
\hline 20 & Trametes versicolor MUT3403 & $86.4 \pm 13.2$ & $60.9 \pm 8.6$ & $87.8 \pm 2.8$ \\
\hline
\end{tabular}

ANT-anthracene; PHEN-phenanthrene; FLU—fluorene.

GC analysis revealed the presence of additional peaks of products of degradation of anthracene, phenanthrene, and fluorene by the studied fungi. These products were identified as 9,10-anthraquinone ( $R T=4.51 \mathrm{~min}$ ), phenanthrene-9,10-quinone ( $R T=5.04 \mathrm{~min})$, and 9-fluorenone ( $\mathrm{RT}=4.33 \mathrm{~min})$ in the case of anthracene, phenanthrene, and fluorene oxidation, respectively. The products of deeper PAH degradation, such as 2-carboxybenzaldehyde, $2,2^{\prime}$-diphenic and phthalic acids, were identified with all studied members of the genera Trametes and Pleurotus, and with S. commune. When the growth time was extended, these compounds disappeared, which suggests their involvement in the basal metabolism [51]. It should be noted that the revealed metabolites of three-ring PAH degradation by the basidio- and ascomycetes were identical.

The most active degraders of three- and four-ring PAHs were the basidiomycetes B. adusta, P. ostreatus (all strains used), S. commune, T. maxima, and T. versicolor (both strains used), and two ascomycetes C. herbarum and L. aphanocladii (Table 1). Although S. murashkinskyi revealed a high degradative activity towards PAHs, it was a slowly growing fungus that can complicate its following practical use. However, despite its average degradative activity, the litter-decomposing $S$. rugosoannulata can be promising for further studies, because soil is the natural habitat of this fungus.

According to the availability to the fungal cells, the studied PAHs can be arranged in the order anthracene $\rightarrow$ phenanthrene $\rightarrow$ fluorene. Comparison of the obtained data with the physicochemical properties of these substances suggests that in this case, a coupling of two factors is essential: the solubility and ionization potentials of PAHs. Although anthracene has the lowest ionization potential $(7.43 \mathrm{eV})$, the low solubility of this substance $(0.07 \mathrm{mg} / \mathrm{L})$ makes its molecules poorly available for the fungal attack. Yet, the well- 
soluble phenanthrene $(1.8 \mathrm{mg} / \mathrm{L})$ has a sufficiently high ionization potential $(8.03 \mathrm{eV})$, and as a consequence, its middle availability for the studied fungi. Finally, a "successful" combination of low ionization potential $(7.88 \mathrm{eV})$ and high solubility $(1.98 \mathrm{mg} / \mathrm{L})$ makes fluorene the most accessible among the PAHs studied.

Now, many reviews on the biodegradation of this class of pollutants have already been published. The corresponding PAH-based quinones (e.g., 9,10-anthraquinone, phenanthrene9,10-quinone, benzo[a]anthracene-7,12-quinone) are discussed as the main metabolites [38,49]. Two possibilities for the formed quinones are known. One is the subsequent utilization of quinone metabolites, as it was shown for P. ostreatus, P. eringii, Phanerochaete laevis, and Polyporus sp. S133. In this case, phthalic and 2,2'-diphenic acids resulted from "deep" degradation of fluorene, phenanthrene, and anthracene. The involvement of these metabolites to basic metabolism and their subsequent mineralization to $\mathrm{CO}_{2}$ are possible, and another possibility is that they can be the end metabolites of PAH degradation; their accumulation was found in Phanerochaete chrysosporium, B. adusta, and Pycnoporus sanguineus.

In our experiments, some differences were also found. The end metabolites of the degradation of PAHs by S. rugosoannulata were quinone derivatives: 9,10-anthraquinone, phenanthrene-9,10-quinone, and 9-fluorenone. During PAH degradation by both Trametes strains, the traces of the corresponding quinones were found. Similar metabolites were detected during cultivation of P. ostreatus strains, S. commune, and B. adusta. They disappeared when the cultivation time was extended. This indicated that they were utilized further. Phthalic acid was the metabolite resulting from "deep" degradation of anthracene and fluorene by $P$. ostreatus strains. The 2,2'-diphenic and phthalic acids were produced by "deep" phenanthrene degradation by these fungi. These metabolites can be included in the basal metabolism of the fungi. The proposed metabolic pathways of three-ring PAH degradation by studied fungi are shown in Figure 1.

\subsubsection{Decolorization of Anthraquinone-Type Dyes}

The three-ring structure of anthraquinone (the metabolite of the fungal degradation of anthracene), occupies the central part of a range of dyes, the so-called anthraquinonetype dyes. These dyes are considered to be the most stable among the different classes of dyes currently used [52,53]. Their entry to the environment with waste water is a serious problem. Many industrial dyes are toxic mutagenic and carcinogenic [54,55]. Although anthraquinone dyes are a large group of synthetic dyes, PolyR-478 and Remazol Brilliant Blue R (RBBR) are most often used as models of similar dyes in biodegradation studies [56].

In our study, two other dyes of this type (Acid Blue 62 and Reactive Blue 4), which differed by substituents at the anthraquinone structure, were chosen. All the studied fungi decolorized anthraquinone dyes, and both the chromophore part of the molecule and the aromatic ring were available for the fungal degradation. Figure 2 (top) shows the chemical structures of these dyes. This evidenced by a decrease in absorption at the UV and visible regions of the spectra of Acid Blue 62 and Reactive Blue 4. Most strains of basidiomycetes decolorized both dyes after 6 days (Figure 2). An exception was S. commune, which decolorized Reactive Blue 4 only by $60 \%$.

The decolorization of Acid Blue 62 resulted in the change of color from dark blue to light reddish-brown. This destruction of the molecule was accompanied by the formation of precipitate, which may indicate the polymerization of the products formed, similar to data obtained by Sugano et al. [54]. The degradation of Reactive Blue 4 was more complete, as can be judged by the complete decolorization of the cultivation medium (Figure 2, photo).

Both dyes were less accessible to the ascomycetes. Decolorization varied from $40 \%$ for G. candidum to $70 \%$ for L. aphanocladii. An exception was C. herbarum, which decolorized both studied dyes completely, without marked sorption by mycelia.

As seen from Figure 2, the ligninolytic fungi (P. ostreatus strains, Trametes species, B. adusta, L. betulina, and Str. rugosoannulata) and ascomycetes (F. oxysporum and C. herbarum) actively decolorized anthraquinone-type dyes. This property can be indirect evidence of 
production of ligninolytic enzymes (laccase and Mn-peroxidase) by these fungi under studied conditions.

A

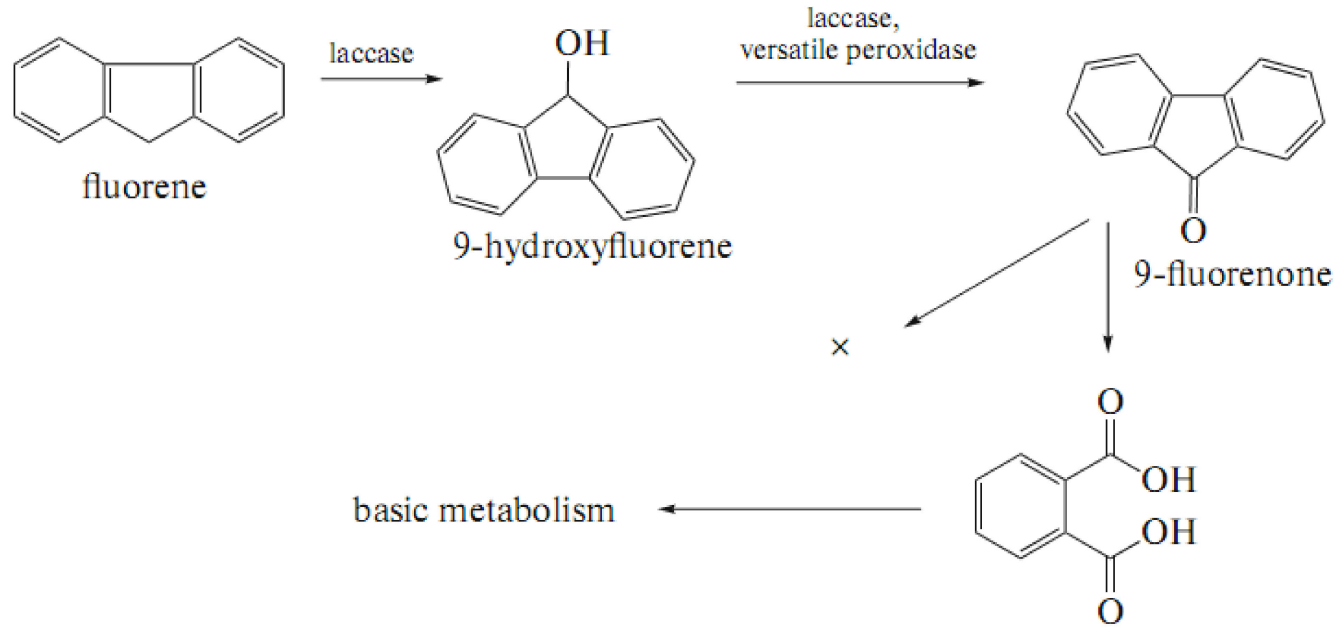

phthalic acid

B

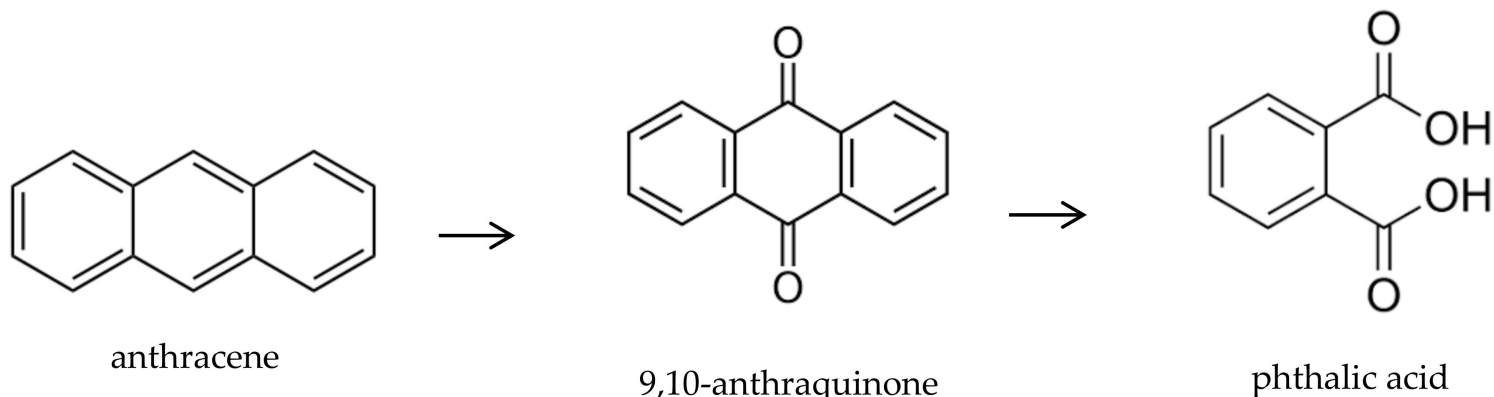

C

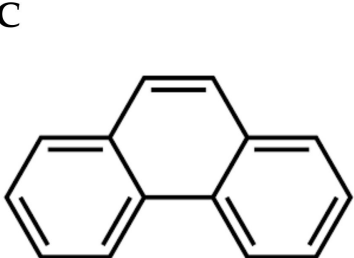

phenanthrene<smiles>CCc1cccc2c1C(=O)C(=O)c1ccccc1-2</smiles>

phenanthrene-9,10-qui-<smiles>Cc1ccc(-c2ccccc2C(=O)O)c(C(=O)O)c1</smiles>

2,2'-diphenic acid<smiles>Cc1cccc(C(=O)O)c1C(=O)O</smiles>

phthalic acid

none

Figure 1. The proposed metabolic pathways of fluorene (A), anthracene (B), and phenanthrene (C) degradation. 
Acid Blue 62<smiles>Nc1c(NC2CCCCC2)cc(S(=O)(=O)O)c2c1C(=O)c1ccccc1C2=O</smiles>

Reactive Blue 4

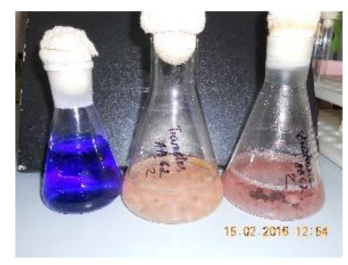

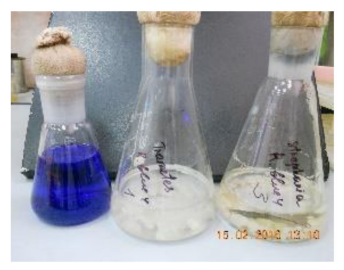
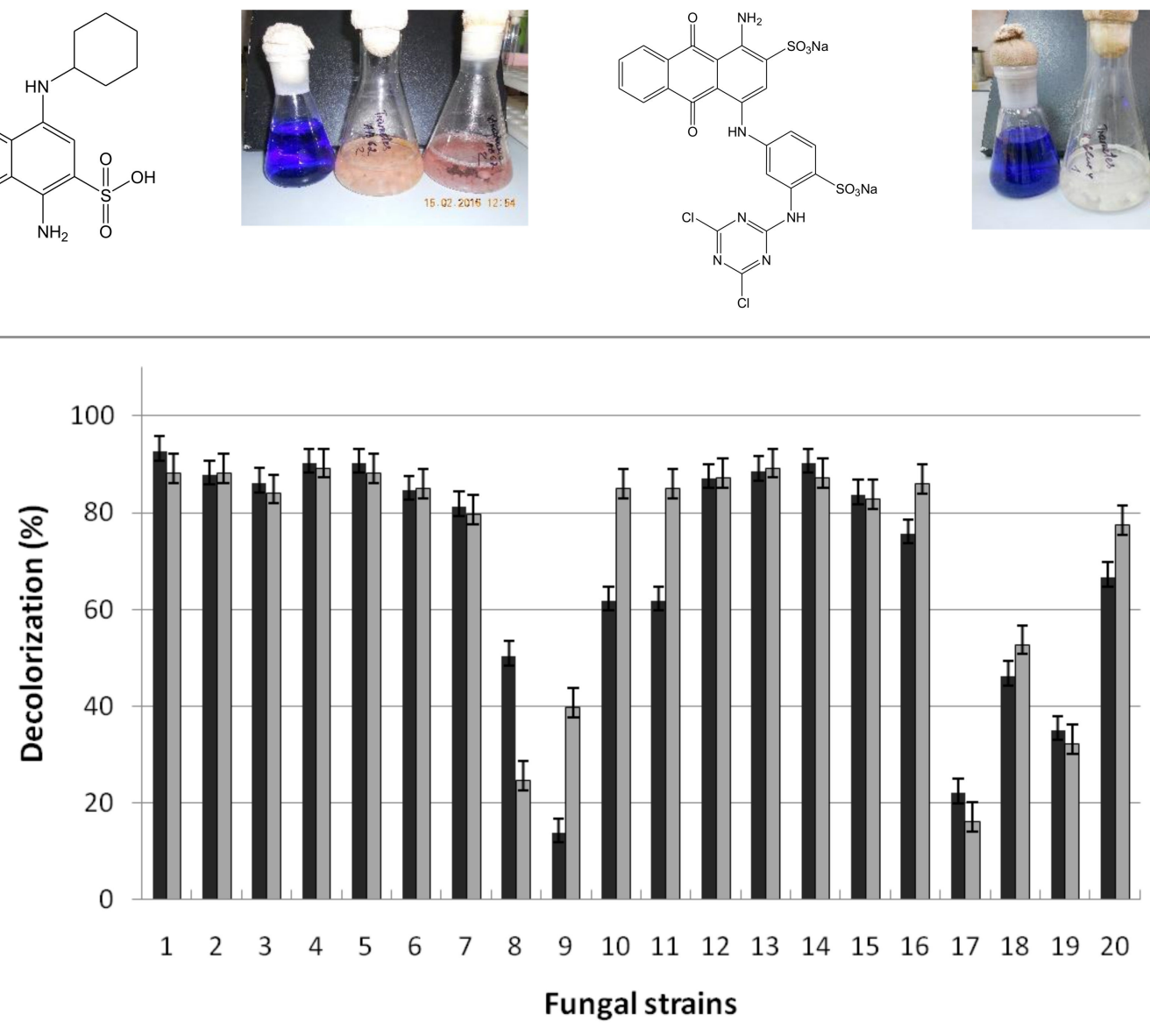

Acid Blue $62 \quad \square$ Reactive Blue 4

Figure 2. Anthraquinone dyes decolorization after 2 days' cultivation of the studied fungi: $1-P$. ostreatus f. Florida, 2-P. ostreatus MUT2977, 3-P. ostreatus 336, 4-P. ostreatus D1, 5-P. ostreatus LEBIN0432, 6-B. adusta, 7-Len. betulina, 8-St. murashkinskyi, 9-Sch. commune, 10-Str. rugosoannulata, 11-T. versicolor DSM11372, 12-T. versicolor MUT3403, 13-T. hirsuta, 14-T. maxima, 15-T. ochracea, 16-T. gibbosa, 17-Lec. aphanocladii, 18-F. oxysporum, 19-G. candidum, 20-C. herbarum.

\subsubsection{Oil Disappearance}

Creosote and oil are complex pollutants that cause serious environmental problems $[11,12,15,57]$. The use of the ligninolytic fungi for the remediation of the soils contaminated by such mixtures has been discussed $[10,11]$. We studied the ability of the fungi to metabolize oil to assess their mycoremediation potential. Most wood-inhabiting basidiomycetes actively utilized oil; the disappearance was 72 to $92 \%$ during 14 days of cultivation (Figure 3A). The exceptions were B. adusta, S. murashkinskyi, and two members of the genus Trametes (T. ochracea and T. gibbosa). Litter-decomposing S. rugosoannulata removed up to $90 \%$ of oil. The studied ascomycetes remove oil actively, too. The disappearance varied from 60 to $84 \%$ with the exception of G. candidum (the decrease did not exceed $46 \%$ ). Weak activity of different strains of G. candidum towards oil hydrocarbons has been shown before [58].

An increase of biomass of the fungi was observed in all treatments; the mycelium grew in the form of pellets of various sizes. Figure 3C shows the growth of the fungi P. ostreatus D1 and S. rugosoannulata in the basidiomycetes-rich environment with oil after 14 days. 
A

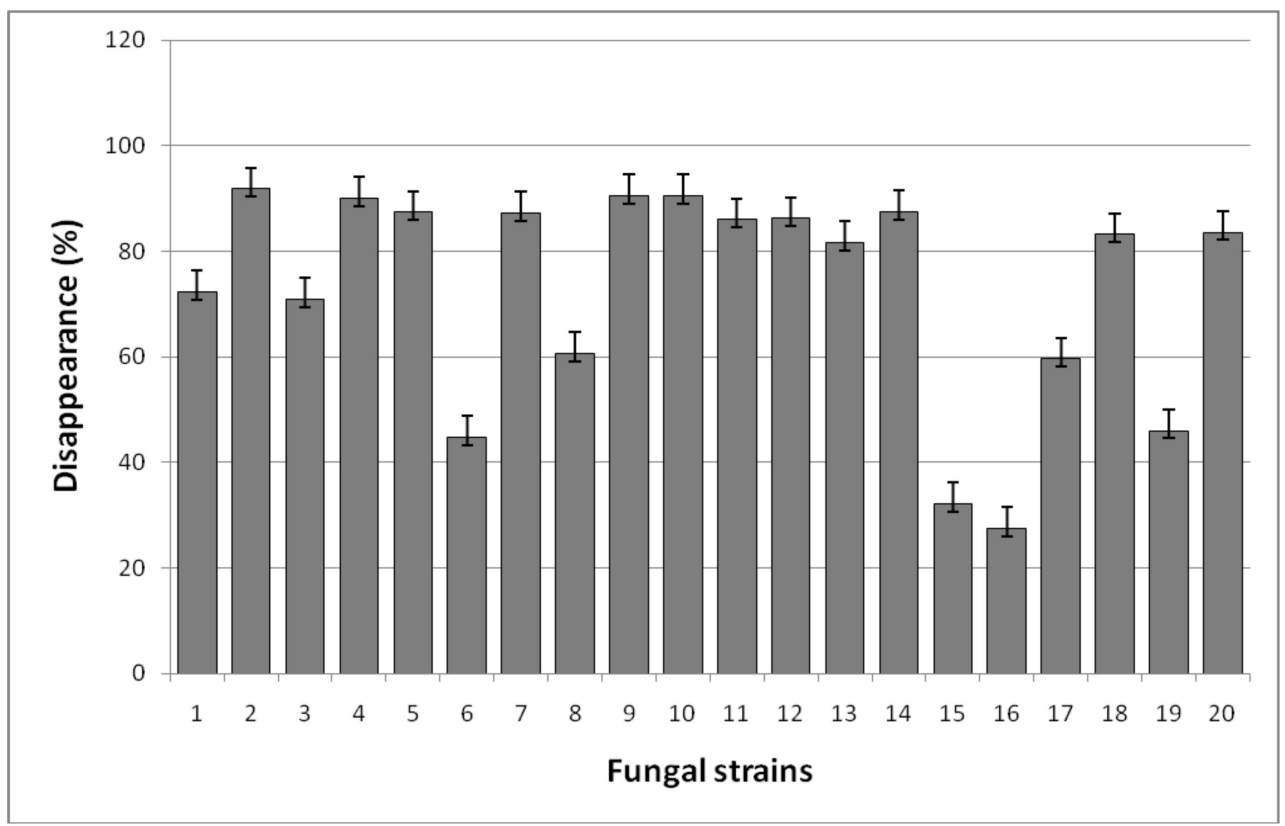

1-P. ostreatus f. Florida, 2-P. ostreatus MUT2977, 3-P. ostreatus 336, 4-P. ostreatus D1, 5-P. ostreatus LE-BIN0432, 6-B. adusta, 7-Len. betulina, 8-St. murashkinskyi, 9-Sch. commune, 10-Str. rugosoannulata, 11-T. versicolor

DSM11372, 12-T. versicolor MUT3403, 13-T. hirsuta, 14-T. maxima, 15-T. ochracea, 16-T. gibbosa, 17-Lec. aphanocladii, 18-F. oxysporum, 19-G. candidum, 20-C. herbarum.

B

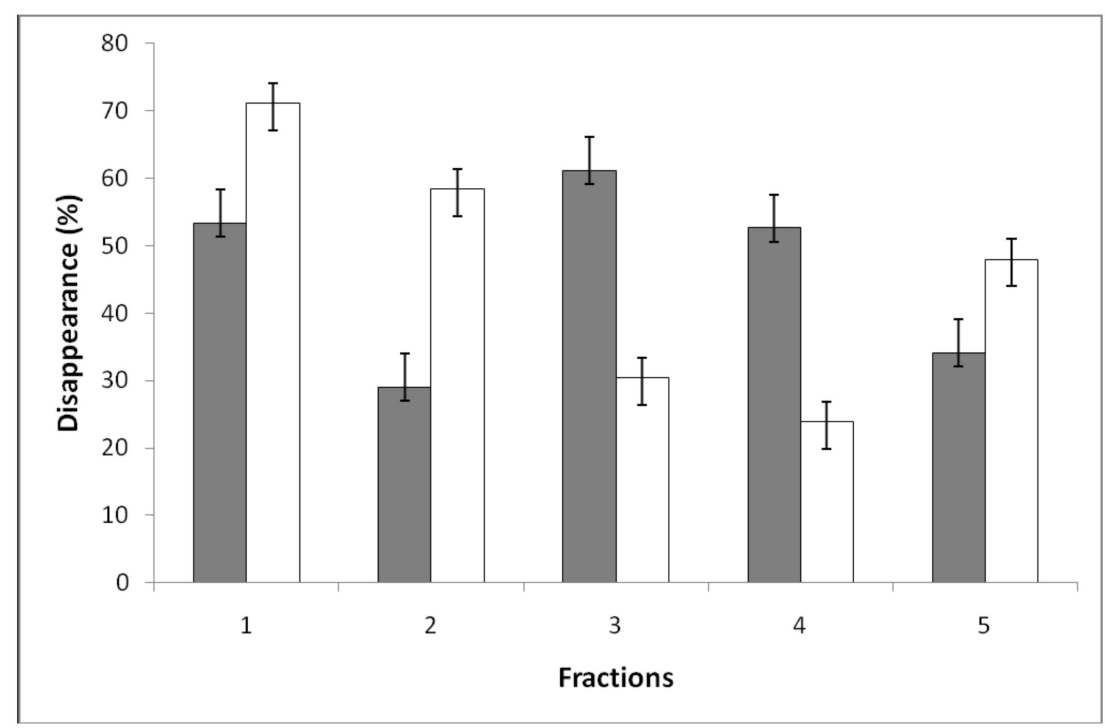

1-alkanes, 2-naphthenes, 3-low-molecular weight aromatic hydrocarbons, 4-high-molecular weight aromatic hydrocarbons, 5-tars.
C

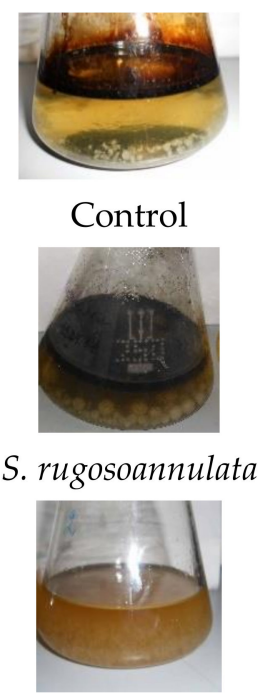

P. ostreatus D1

Figure 3. Oil disappearance by studied fungi (A), disappearance of fractions of oil degradation during growth of P. ostreatus D1 $(\square)$ and Str. rugosoannulata $(\square)$ in basidiomycetes-rich medium (B), and the fungal growth (C). 
The study of changes of fraction composition of oil revealed some differences among the fungi used. Wood-inhabiting basidiomycete $P$. ostreatus D1 utilized all fractions of oil with the exception of naphthenes. Their disappearance varied from 52 to $66 \%$ (Figure 3B). Whereas soil-inhabiting $S$. rugosoannulata more actively degrade alkanes and naphthenes, fractions of low- and high-molecular-weight aromatic hydrocarbons were less accessible to this fungus (Figure 3B). This can result from the low activities of ligninolytic enzymes produced by $S$. rugosoannulata in comparison with $P$. ostreatus.

\subsubsection{Surfactant Degradation}

The use of different surfactants can stimulate desorption of hydrophobic pollutants from soil and increase their bioavailability $[16,17]$. Often Tween-40, Tween-80, and Triton X100 are used. For example, PAH degradation in polluted soil by P. ostreatus can be increased with Tween-40, Tween-80, and Triton X-100 [59,60]. Tweens do not affect the growth of fungi and are catabolized by them [61]. Significant range of the surfactants (such as oxyethylated alkylphenols) often more effectively increases the solubility of hydrophobic compounds. However, some surfactants themselves are very difficult to degrade, resulting in the formation of stable and toxic end products and their accumulation in the environment $[18,19]$. The possibility of practical use of these compounds in bioremediation processes can be limited by their resistance to degradation. In addition, a result of their degradation can be the formation of stable and toxic alkylphenols as final products. Bacterial degradation of this class of compounds has been studied quite well, but the information on their degradation by fungi is limited [62].

We used neonol AF9-12 as an example of oxyethylated alkylphenols. Although it was not toxic for all the fungi studied, only 17 fungi metabolized this compound, and the degree of degradation and the site of the attack of its molecule are different (Figure 4).

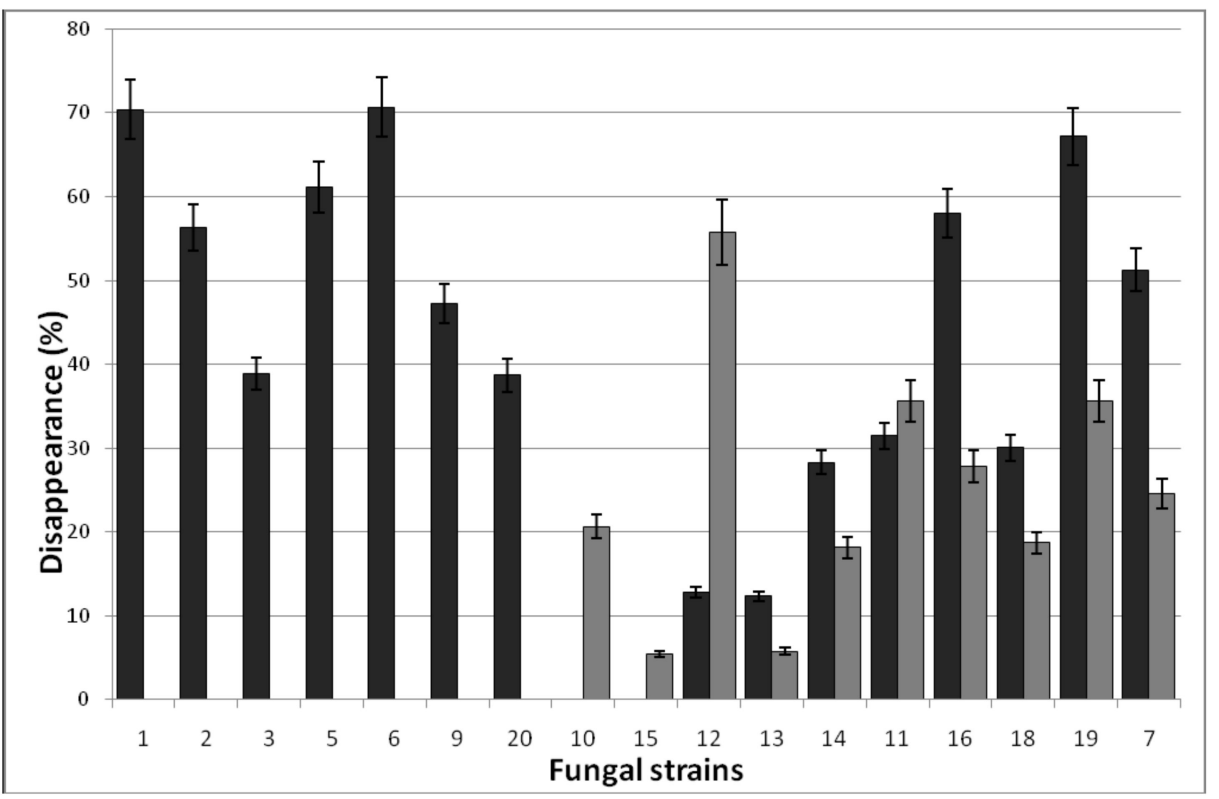

Figure 4. The disappearance of neonol AF9-12 by studied fungi: $1-P$. ostreatus $\mathrm{f}$. Florida, $2-P$. ostreatus MUT2977, 3-P. ostreatus 336, 5-P. ostreatus LE-BIN0432, 6-B. adusta, 7-Len. betulina, 9-Sch. commune, 10-Str. rugosoannulata, 11-T. versicolor DSM11372, 12-T. versicolor MUT3403, 13-T. hirsuta, 14-T. maxima, 15-T. ochracea, 16-T. gibbosa, 18-F. oxysporum, 19-G. candidum, 20-C. herbarum; ——oxyethyl chain, ——aromatic ring.

The use of spectrophotometric methods $[28,29]$ revealed that basidiomycetes $P$. ostreatus f. Florida, P. ostreatus MUT, P. ostreatus 336, P. ostreatus LE-BINB, B. adusta, S. commune, and ascomycete $C$. herbarum attacked the oxyethyl chain, while the aromatic ring remained intact. S. rugosoannulata and T. ochracea degraded the aromatic ring. 
Finally, another nine species of the fungi, including basidiomycetes L. betulina, T. versicolor DSM, T. versicolor MUT, T. hirsuta, T. maxima, and T. gibbosa, and ascomycetes L. aphanocladii, F. oxysporum, and G. candidum, destroyed both parts of the neonol molecule (Figure 4).

The cleavage of the oxyethyl side chain leads to the formation of the alkylphenols. In our work we used isononylphenol as model of alkylphenols to study the activity of fungi. Isononylphenol decreased the growth of the most studied fungi, as evidenced by the significant decrease of the amount of biomass compared to the control treatment (Figure 5A). The exceptions were fungi S. murashkinskyi, T. hirsuta, T. ochracea, F. oxysporum, and G. candidum. The amounts of the mycelium of these fungi in the control treatments and in the presence of isononylphenol were approximately the same. An increase (by 1.5 times) of biomass of F. oxysporum in the presence of this pollutant was found.

Among 20 studied fungi, only six species of basidiomycetes (T. versicolor MUT, L. betulina, P. ostreatus f. Florida, S. rugosoannulata, S. commune) and one ascomycete (C. herbarum) could degrade isononylphenol. The most active degrader of the isononylphenol was S. commune; the disappearance was $61 \%$ after 14 days of cultivation at the start concentration of $200 \mathrm{mg} / \mathrm{L}$ (Figure 5A).

Infrared spectroscopy is widely used to study the fine structural changes in molecules of various chemical compounds and materials. This method is widely used in studying the ways of degradation of various alkylphenols [63-65]. We used fungi to study changes in surfactant structure during fungal degradation: P. ostreatus Florida (attacked the oxyethyl chain), S. rugosoannulata (degraded the aromatic ring), T. versicolor DSM (both parts of the neonol molecule), and $S$. commune (the most active degrader of isononylphenol).

In the IR spectra of samples, the degradation of neonol P. ostreatus Florida (Figure S1) mutually altered the intensity of the absorption bands in the 2958 and $2926 \mathrm{~cm}^{-1}$ region, corresponding to the antisymmetric and symmetric $\mathrm{CH}$ vibrations of the alkyl chain, and 2874 and $2858 \mathrm{~cm}^{-1}$, corresponding to antisymmetric and symmetric $\mathrm{CH}$ aromatic rings. It indicates an increase in the fraction of absorption of the latter. This fact is also supported by an increase in the intensity of deformation bands at $1453 \mathrm{~cm}^{-1}$ and skeletal vibrations at $1252 \mathrm{~cm}^{-1}$ alkyl fragments. Some authors associate an increase in absorption at $1252 \mathrm{~cm}^{-1}$ with the formation of aromatic esters during the degradation of alkylphenols. In addition, there is a significant increase in band absorption at $1402 \mathrm{~cm}^{-1}$, which is associated with the deformation vibrations of the $\mathrm{OH}$ group, and the increase in intensity usually indirectly indicates the formation of hydrogen bonds, which indicates the appearance in the medium of polar components originating from the original neon by shortening the hydroxyethyl fragment.

The notable changes in the IR spectra of samples obtained after neonol degradation by S. rugosoannulata (Figure S2) were revealed. The wide absorption band of $\mathrm{OH}$ groups at $3365 \mathrm{~cm}^{-1}$ shows a shift of about $80 \mathrm{~cm}^{-1}$ toward higher frequencies. It indicates the degradation of some hydrogen bonds and a certain increase of the proportion of hydrophobic components. The absorption bands of antisymmetric and symmetric vibrations of alkyl fragments at 2974 and $2927 \mathrm{~cm}^{-1}$, respectively, become more pronounced compared to the spectra of control treatment. Two bands in the region of symmetric and antisymmetric vibrations of $\mathrm{C}-\mathrm{H}$ in aromatic rings degenerate into one, broadened with a maximum at $2883 \mathrm{~cm}^{-1}$ after degradation. It is also characteristic of stretching vibrations of $\mathrm{C}-\mathrm{H}$-saturated hydrocarbons. The intense absorption at $881 \mathrm{~cm}^{-1}$, which is characteristic of 1,4-disubstituted benzenes, completely disappears, while the intensity of the stretching vibrations of the $\mathrm{C}-\mathrm{OH}$ end groups of polyoxyethyl substituents at 1049 and $1089 \mathrm{~cm}^{-1}$ decreases significantly. In addition, there is a pronounced absorption at $1115 \mathrm{~cm}^{-1}$, characteristic of acetals. These data can show the destruction of aromatic rings during the degradation of neonol. 
A

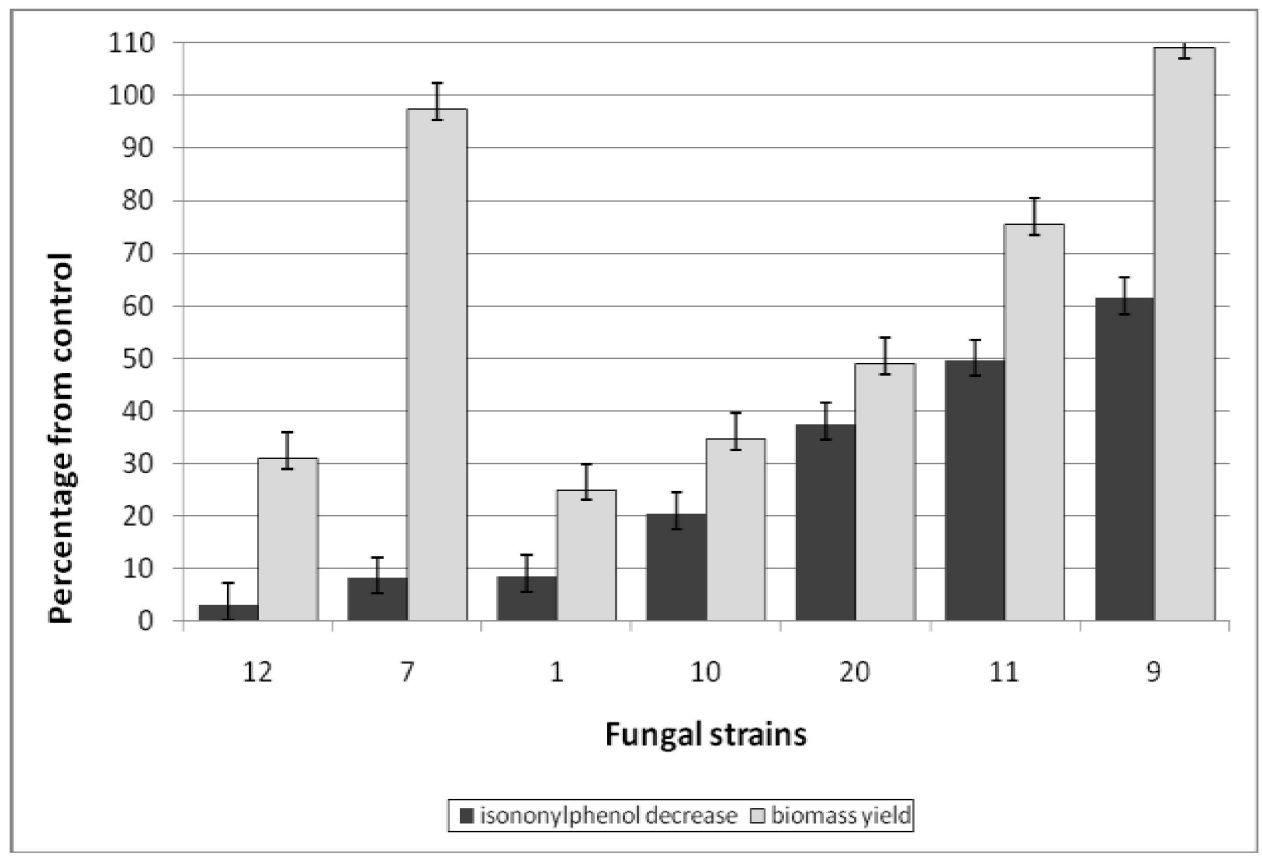

B

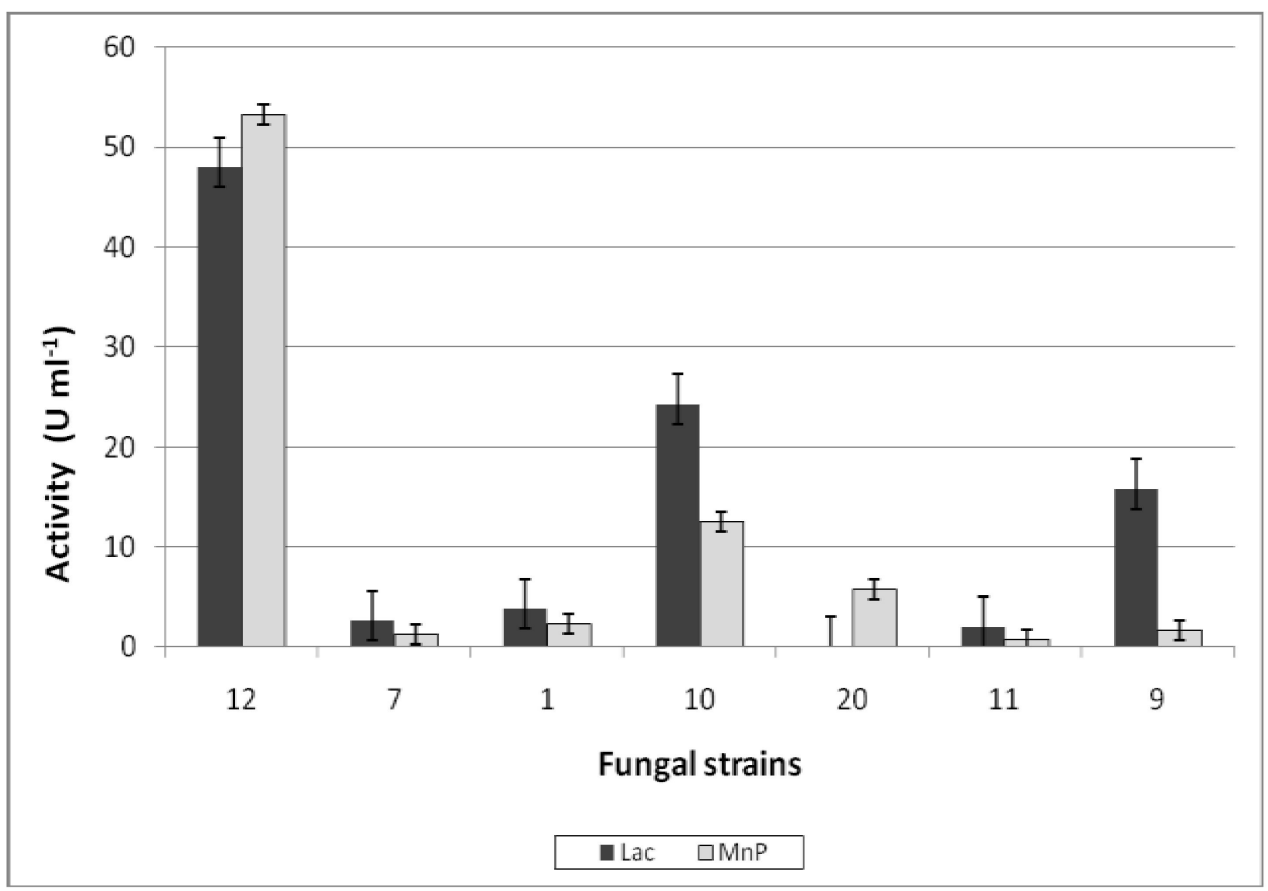

Figure 5. The isononylphenol disappearance and biomass yield (A) and ligninolytic enzymes production (B) during growth of studied fungi at the presence of isononylphenol: $1-P$. ostreatus f. Florida, 7-L. betulina, 9-S. commune, 10-S. rugosoannulata, 11-T. versicolor DSM11372, 12-T. versicolor MUT3403, 20-C. herbarum.

In the IR spectra of samples after the degradation of neonol T. versicolor DSM (Figure S3), the changes analogous to those described above are observed. Thus, the absorption bands of antisymmetric and symmetric vibrations of alkyl fragments at 2957 and $2925 \mathrm{~cm}^{-1}$, respectively, as well as the corresponding bands of antisymmetric and symmetric vibrations 
of $\mathrm{CH}$ of aromatic rings at 2874 and $2860 \mathrm{~cm}^{-1}$, become less intense compared to the control spectra. There is also a decrease in the intensity of the bands attributable to the vibrations of the C-O-C groups of the hydroxyethyl fragment at 1037 and $1106 \mathrm{~cm}^{-1}$, as well as the absorption bands characteristic of the deformation vibrations of the $\mathrm{CH}$ groups of alkyl chains. The appearance of an absorption band at $1294 \mathrm{~cm}^{-1}$, which is associated with dimers of carboxylic acids, is noteworthy. The appearance of carboxylic acids can be explained by oxidative degradation of aromatic rings of alkylphenols. Thus, based on the spectral data, it is possible to draw a conclusion about the most probable destruction of some of the neonol molecules affecting both aromatic rings and polyoxyethyl fragments.

Isononylphenol is a product of incomplete degradation of oxyethylated alkylphenol. Since the structure of isononylphenol does not include polyoxyethyl substituents and has free phenolic hydroxyl, IR spectra of the isononylphenol and neonol differ significantly due to the manifestation of the isononyl substituent bands. There is an intense absorption in the isononylphenol spectrum in the form of a somewhat broadened peak at $1456 \mathrm{~cm}^{-1}$, which refers to the deformation vibrations of methylene units, and intensive absorption at $1379 \mathrm{~cm}^{-1}$, related to the vibrations of the isopropyl fragment. The vibrations of the aromatic ring are more vivid and intensive at 1596 and $1513 \mathrm{~cm}^{-1}$. Analysis of IR spectra of samples after degradation of isononylphenol by S. commune (Figure S4) reveals significant changes. The intensity of the bands characteristic for deformation vibrations of alkyl fragments at $1379-1456 \mathrm{~cm}^{-1}$, as well as vibrations of aromatic rings close to $1500,1600 \mathrm{~cm}^{-1}$, is significantly reduced. The intensive absorption band at $830 \mathrm{~cm}^{-1}$, which is attributed to the vibrations of disubstituted benzene rings, completely disappears. Simultaneously, there is a significant decrease in the intensity of antisymmetric and symmetric vibrations of both aliphatic and aromatic CH fragments in the region of $2960-2853 \mathrm{~cm}^{-1}$. All this indicates the destruction, to a large extent, of the structure of both aromatic rings and alkyl substituents of isononylphenol. Oxidative destruction of aromatic rings of isononylphenol is confirmed by the appearance of weak absorption bands at $1727-1739 \mathrm{~cm}^{-1}$, characteristic of the carbonyl groups of the carboxyl fragment.

Subsequent use of GC revealed three metabolites of neonol degradation by the fungus T. versicolor DSM with retention times of 5.50 to $5.76 \mathrm{~min}$. Metabolite with retention time of 5.73 min was detected after degradation of isononylphenol by S. commune. The presence of products with similar retention times suggests that the degradation of neonol T. versicolor DSM and isononylphenol S. commune at a certain stage can pass along a similar path.

\subsection{The Study of the Phytotoxicity of Parent Compounds and Metabolites Revealed}

Phytotesting as a fast toxicological examination of the media is widely used now. The main parameters taken into account are usually germinating capacity and germinating power, average length of the root, average length of the shoot, development of root hairs, and root orientation. The most informative characteristics are root development (length) and germinating power. In our experiments the effects of the parent PAHs and its fungal metabolites on sorghum germination, length of shoots, and length of roots were checked (Figure 6). Control levels represent the corresponding values (germination of seeds, length of shoots, length of roots) in control treatments (without pollutants).

Phytotests showed that the effects of PAHs and their derivatives agree with aqueous solubility of the tested compounds. PAHs, as poorly soluble compounds, were less phytotoxic than their oxidized derivatives. Oxidized PAH metabolites presented by quinones, ketones, and acids are more soluble in water than PAH; therefore, their phytotoxicity can be greater. Being more hydrophilic and electrophilic, these compounds are more capable of forming covalent bonds with numerous cell structures $[66,67]$ and producing a pronounced toxic effect on plants. In nature, oxidized derivatives of PAH can arise rather intensely under the effect of physicochemical factors [68] and as a result of microbial degradation of hydrocarbons $[69,70]$. Greater toxicity of contaminated soil may depend exactly on more toxic microbial metabolites arising as a result of oil decomposition [71]. At the same time, the toxic effect produced by oxidized metabolites of PAH and possible fate of these com- 
pounds in soil biocenoses should be taken into account. It should be noted that oxidized derivatives of PAH are not only more easily available to soil microflora [72] but also are capable of impairing enzyme systems in plants [73].

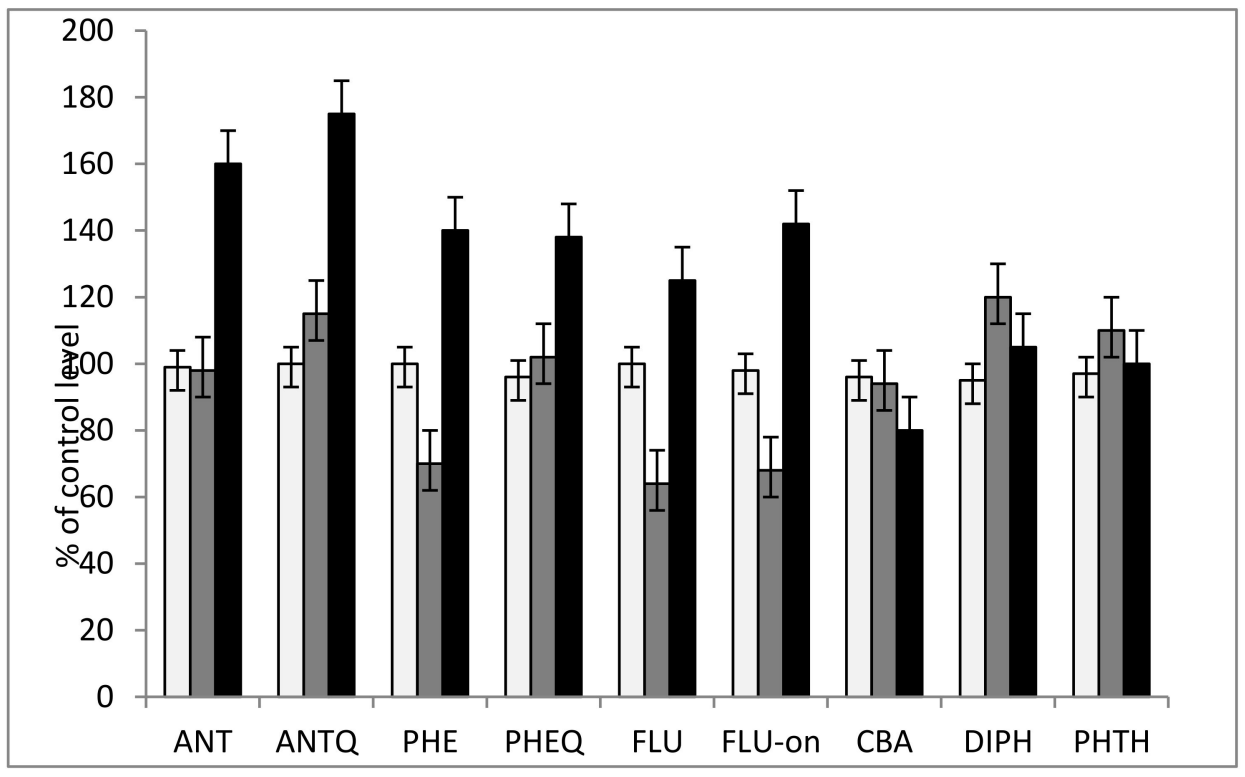

Figure 6. Effect of PAHs and their fungal metabolites on germination of seeds ( $\square$ ), length of shoots $(\square)$, and length of roots $(\square)$ of sorghum: ANT—anthracene, ANTQ-9,10-anthraquinone, PHEphenanthrene, PHEQ-phenanthrene-9,10-quinone, FLU -fluorene, FLU-on-9-fluorenone, CBA-2carboxybenzaldehyde, DIPH-2,2'-diphenic acid, PHTH—phthalic acid.

\subsection{Study of Adaptive Properties of Fungi}

Three different aspects were evaluated in our experiments: (1) the ligninolytic enzymes, which play a key role in the degradation of aromatic compounds by ligninolytic fungi; (2) emulsifying compounds production, which can increase solubility of hydrophobic compounds and promote the catalytic action of ligninolytic enzymes; (3) extracellular polysaccharides production, which can be depot for ligninolytic enzymes.

\subsubsection{Ligninolytic Enzymes Production}

As mentioned above, the key stages of the degradation of aromatic pollutants, including PAHs, can catalyze ligninolytic enzymes. We have shown that the degradation of PAHs by the studied basidiomycetes was accompanied by the production of ligninolytic enzymes (Table 2). All representatives of the genera Pleurotus, Trametes, as well as L. betulina, S. murashkinskyi, and S. commune, produced laccases and Mn-peroxidases. Lignin peroxidase and Mn-peroxidase activities were revealed in B. adusta, whereas S. rugosoannulata had only laccase. It was first found that the PAH degradation by ascomycetes L. aphanocladii, F. oxysporum, and C. herbarum was accompanied by the production of peroxidases. In G. candidum, the activities of these enzymes were not revealed. Perhaps the low degradative activity of this fungus towards PAHs is the result of this.

A study of the production of ligninolytic enzymes during the decolorization of dyes showed that all basidiomycetes produced laccases and Mn-peroxidases, whereas ascomycetes showed only peroxidase activity (Table 2). We have previously shown that both investigated dyes are available for both ligninolytic peroxidases and laccases [30]. Apparently, the activity of only peroxidase (in the case of ascomycetes) is not enough for complete decolorization of these dyes. The decolorization activity of G. candidum suggested the production of peroxidase. This enzyme oxidized 2,6-dimethoxyphenol and anthraquinone-type dyes [74]. 
Table 2. Activities of extracellular enzymes $(\mathrm{U} / \mathrm{mL})$ after 14 days of the cultivation of the studied fungi both with and without pollutants.

\begin{tabular}{|c|c|c|c|c|c|c|c|c|c|}
\hline \multirow{3}{*}{ Fungal Strains } & \multicolumn{9}{|c|}{ Activity, U/mL } \\
\hline & \multirow{2}{*}{$\begin{array}{l}\text { Control } \\
\text { (without } \\
\text { Pollutant) }\end{array}$} & \multicolumn{8}{|c|}{ Pollutants } \\
\hline & & ANT & PHEN & FLU & Neonol & INP & AB62 & RB4 & Oil \\
\hline B. adusta: LiP & 0 & 42.3 & 9.5 & 37.2 & 49.9 & 94.4 & 0 & 0 & 46.8 \\
\hline $\mathrm{MnP}$ & 0 & 3.2 & 3.4 & 21.5 & 318.2 & 135.0 & 8.0 & 15.0 & 58.3 \\
\hline C. herbarum: PerOx & 0 & 12.3 & 10.4 & 12.2 & 13.1 & 5.8 & 4.7 & 2.0 & 11.2 \\
\hline F. oxysporum: PerOx & 0 & 0.9 & 3.8 & 0.5 & 7.4 & 0.2 & 82.4 & 18.1 & 4.8 \\
\hline G. candidum: PerOx & 0 & 0 & 0 & 0 & 0 & 0 & 0 & 0 & 0 \\
\hline L. aphanocladii: PerOx & 0 & 12.4 & 7.6 & 12.2 & 7.8 & 8.0 & 8.0 & 3.8 & 6.2 \\
\hline L. betulina: Lac & 4.8 & 5.3 & 1.0 & 2.4 & 3.1 & 2.9 & 2.2 & 1.0 & 15.4 \\
\hline $\mathrm{MnP}$ & 3.7 & 21.2 & 22.5 & 21.4 & 7.5 & 1.3 & 12.6 & 4.8 & 14.4 \\
\hline P. ostreatus Florida: Lac & 49.9 & 7.3 & 46.2 & 16.9 & 336.4 & 3.8 & 18.8 & 8.4 & 86.4 \\
\hline $\mathrm{MnP}$ & 242.5 & 38.4 & 78.8 & 14.2 & 741.0 & 2.3 & 5.1 & 5.0 & 136.8 \\
\hline \multicolumn{10}{|l|}{ P. ostreatus MUT2977: } \\
\hline $\mathrm{Lac}$ & 40.1 & 24.9 & 288.5 & 158.2 & 33.3 & 1.4 & 23.4 & 3.6 & 24.0 \\
\hline $\mathrm{MnP}$ & 392.6 & 118.5 & 494.9 & 291.7 & 167.0 & 4.6 & 5.4 & 1.8 & 44.0 \\
\hline P. ostreatus 336: Lac & 98.9 & 33.2 & 3.0 & 0.6 & 3.5 & 1.1 & 73.6 & 7.1 & 56.7 \\
\hline $\mathrm{MnP}$ & 145.6 & 25.9 & 7.1 & 12.2 & 11.5 & 1.2 & 5.1 & 3.6 & 217.9 \\
\hline P. ostreatus D1: Lac & 49.1 & 30.1 & 40.1 & 18.0 & 52.3 & 6.8 & 55.2 & 7.2 & 29.5 \\
\hline $\mathrm{MnP}$ & 403.0 & 112.1 & 456.9 & 355.8 & 283.0 & 17.5 & 68.8 & 10.0 & 139.4 \\
\hline \multicolumn{10}{|l|}{ P. ostreatus LE-BIN0432: } \\
\hline Lac & 64.0 & 16.9 & 2.7 & 1.5 & 34.0 & 3.0 & 88.0 & 5.8 & 18.4 \\
\hline $\mathrm{MnP}$ & 450.1 & 57.0 & 26.2 & 24.0 & 8.2 & 3.0 & 5.1 & 2.7 & 2.5 \\
\hline S. commune: Lac & 26.8 & 11.1 & 13.2 & 15.9 & 15.4 & 5.0 & 8.8 & 7.9 & 14.2 \\
\hline $\mathrm{MnP}$ & 86.3 & 3.0 & 27.5 & 3.4 & 1.6 & 0.4 & 20.8 & 12.3 & 1.0 \\
\hline $\mathrm{LiP}$ & & & & & & 12.5 & & & \\
\hline S. murashkinskyi: Lac & 10.1 & 13.6 & 44.0 & 18.0 & 215.1 & 31.8 & 12.2 & 15.6 & 24.0 \\
\hline $\mathrm{MnP}$ & 12.8 & 14.2 & 16.6 & 22.3 & 249.7 & 35.7 & 18.3 & 18.8 & 29.1 \\
\hline S. rugosoannulata: Lac & 2.1 & 5.1 & 4.8 & 2.7 & 34.7 & 11.7 & 15.5 & 13.2 & 8.7 \\
\hline $\mathrm{MnP}$ & 7.2 & 1.3 & 2.5 & 1.0 & 104.0 & 43.7 & 17.3 & 14.7 & 23.6 \\
\hline $\mathrm{LiP}$ & & & & & 58.0 & & & & \\
\hline T. gibbosa: Lac & 23.3 & 26.4 & 26.5 & 24.8 & 39.0 & 3.1 & 20.0 & 22.3 & 99.5 \\
\hline $\mathrm{MnP}$ & 48.4 & 61.5 & 70.7 & 41.2 & 7.5 & 0.6 & 14.9 & 9.6 & 17.5 \\
\hline T. hirsuta: Lac & 32.2 & 18.5 & 13.7 & 26.3 & 174.8 & 9.8 & 39.0 & 4.0 & 98.5 \\
\hline $\mathrm{MnP}$ & 56.6 & 49.0 & 110.8 & 199.3 & 202.0 & 14.6 & 7.5 & 0.6 & 17.7 \\
\hline T. maxima: Lac & 15.5 & 13.7 & 3.1 & 6.6 & 308.9 & 26.6 & 13.9 & 4.2 & 12.2 \\
\hline $\mathrm{MnP}$ & 16.1 & 14.4 & 6.5 & 31.5 & 72.3 & 6.9 & 42.5 & 14.2 & 18.6 \\
\hline T. ochracea: Lac & 9.3 & 7.2 & 7.1 & 6.0 & 394.1 & 31.3 & 9.4 & 10.5 & 4.8 \\
\hline $\mathrm{MnP}$ & 50.1 & 166.3 & 48.3 & 32.2 & 50.4 & 6.3 & 5.5 & 2.8 & 3.2 \\
\hline \multicolumn{10}{|l|}{ T. versicolor DSM11372: } \\
\hline $\mathrm{Lac}$ & 3.4 & 126.0 & 141.6 & 73.7 & 1.9 & 2.0 & 35.5 & 4.0 & 8.2 \\
\hline $\mathrm{MnP}$ & 24.1 & 9.6 & 15.3 & 10.4 & 17.5 & 0.8 & 17.5 & 1.2 & 18.3 \\
\hline $\mathrm{LiP}$ & & & & & 16.6 & & & & 23.7 \\
\hline \multicolumn{10}{|l|}{ T. versicolor MUT3403: } \\
\hline $\mathrm{Lac}$ & 76.7 & 103.4 & 17.6 & 164.0 & 32.0 & 48.0 & 32.1 & 48.1 & 49.5 \\
\hline $\mathrm{MnP}$ & 47.9 & 128.5 & 64.1 & 86.4 & 149.5 & 53.2 & 14.9 & 5.3 & 13.2 \\
\hline
\end{tabular}


To study the effect of oil on the production of ligninolytic enzymes, we used the basidiomycetes-rich environment, which supports the production laccase and peroxidases. As in the case of other pollutants, the process of the oil degradation by basidiomycetes was accompanied by the production of ligninolytic enzymes. All representatives of the species P. ostreatus, L. betulina produced laccase and Mn-peroxidase, which is a characteristic property of these fungi. The presence of lignin peroxidase was shown in all representatives of the genus Trametes and in the litter-decomposing fungus S. rugosoannulata (Table 2). The activity of this enzyme was absent in the control treatments (without pollutant) and in the presence of PAHs. Perhaps oil can contain any compounds which can act as inducers of this enzyme. Oil degradation by three ascomycetes, as well as the degradation of the other studied pollutants, was accompanied by the production of the single ligninolytic enzyme, peroxidase. The activity of ligninolytic enzymes in G. candidum was not revealed.

The degradation of neonol AF9-12 was accompanied by the production of laccases and Mn-peroxidases by basidiomycetes and only peroxidases in ascomycetes (Table 2). Many authors discuss the Mn-peroxidases, laccases, and cyt P450 as the enzymes which can be involved in alkylphenols degradation. Commonly, ligninolytic fungi can polymerize the alkylphenols or degrade the primary structure of these compounds [75]. The degradation of isononylphenol was accompanied by the production of laccase and Mn-peroxidase in all the mentioned basidiomycetes and peroxidase in ascomycete C. herbarum (Table 2, Figure 5B). In addition, T. versicolor MUT, as a response to the presence of isononylphenol in the cultivation medium, produced lignin peroxidase, in contrast to the control treatment (without pollutant).

Different studies have shown that extracellular ligninolytic enzymes of these fungi are responsible for the initial oxidation of different pollutants, including PAHs. Ligninolytic fungi were found to polymerize alkylphenols as a result of their initial attack by extracellular lignin-modifying enzymes, and to degrade the primary structure of these compounds $[14,24,37,38]$. In our experiments, the study of the activity of the main enzymes of the ligninolytic complex in the cultivation medium with or without pollutants revealed the production of laccase, Mn-peroxidase, and lignin peroxidase. Differences in the activity and composition of the ligninolytic complexes of individual species were noted: P. ostreatus strains, T. versicolor strains, and S. commune produced laccase and $\mathrm{Mn}$ peroxidase; $S$. rugosoannulata produced only laccase under the experimental conditions, and B. adusta produced lignin peroxidase and Mn-peroxidase. Finally, the main active producers of ligninolytic enzymes were fungi belonging to Pleurotus. The degradation of pollutants was accompanied by the production of laccases and Mn-peroxidases in basidiomycetes, whereas the ascomycetes produced only peroxidases. Three from studied basidiomycetes (Sch. commune, Str. rugosoannulata, and T. versicolor) can produce a third ligninolytic enzyme-lignin peroxidase-as response to the presence of neonol AF9-12 or isononylphenol. Thus, among the studied fungi, laccase and Mn-peroxidase are the most common ligninolytic enzymes. Earlier, we showed that the presence of these enzymes is a necessary condition for the complete degradation of PAH [76-78]. The production of ligninolytic laccases and peroxidases in the presence of pollutants can be seen as one of the mechanisms of adaptation of fungi.

\subsubsection{Emulsifying Compounds Production}

One of the strategies of adaptation of microorganisms to contamination by hydrophobic compounds is the production of emulsifying compounds (biosurfactants), which increase the availability of the pollutant for its utilization. Now, separate reports on the production of biosurfactants by ligninolytic fungi are available. We found that the process of degradation of hydrophobic compounds (PAHs, isononylphenol, and oil) by most of the studied fungi was accompanied by the formation of foam, which may serve as an indirect sign of the production of substances with emulsifying activity. For all the studied fungi, we determined the emulsifying activity of the culture liquid after 24 and $48 \mathrm{~h}$ of cultivation (Table 3). 
Table 3. Emulsifying activities of cultivation medium after growth of studied fungi in the presence of hydrophobic pollutants $\left(\mathrm{E}_{48}, \%\right)$.

\begin{tabular}{|c|c|c|c|c|c|}
\hline \multirow{3}{*}{ Fungi } & \multicolumn{5}{|c|}{ Emulsifying Activity $\left(\mathrm{E}_{48}, \%\right)$} \\
\hline & \multirow[b]{2}{*}{ ANT } & \multirow[b]{2}{*}{ PHEN } & & & \\
\hline & & & FLU & INP & oil \\
\hline B. adusta MUT 3398 & $21.8 \pm 3.4$ & $28.2 \pm 3.2$ & $34.0 \pm 3.1$ & $30.4 \pm 13.0$ & $7,6 \pm 1,3$ \\
\hline C. herbarum MUT 3238 & $34.0 \pm 5.5$ & $54.6 \pm 13$ & $24.2 \pm 1.3$ & $13.2 \pm 3.3$ & $32.3 \pm 3.6$ \\
\hline F. oxysporum IBPPM 543 & $47.1 \pm 2.3$ & $0 \pm 0$ & $0 \pm 0$ & $0 \pm 0$ & $27.0 \pm 3,4$ \\
\hline G. candidum MUT4803 & $0 \pm 0$ & $34,3 \pm 5,7$ & $0 \pm 0$ & $54,2 \pm 7,7$ & $6,5 \pm 3,8$ \\
\hline Lec. aphanocladii IBPPM 542 & $19.3 \pm 5.0$ & $12.5 \pm 3.9$ & $6.2 \pm 2.8$ & $0 \pm 0$ & $18.2 \pm 3.7$ \\
\hline Len. betulina LE-BIN 2047 & $69.8 \pm 12.3$ & $21.9 \pm 1.3$ & $38.2 \pm 4.9$ & $47.5 \pm 8.4$ & $60 \pm 5.5$ \\
\hline P. ostreatus f. Florida IBPPM 540 & $65.7 \pm 6.9$ & $38.1 \pm 3.4$ & $0.7 \pm 0.2$ & $26.7 \pm 3.6$ & $30.1 \pm 6.8$ \\
\hline P. ostreatus MUT 2977 & $3.0 \pm 5.2$ & $0 \pm 0$ & $5.0 \pm 8.7$ & $12.3 \pm 4.9$ & $23.2 \pm 3.0$ \\
\hline P. ostreatus 336 & $21.6 \pm 3.7$ & $21.1 \pm 2.5$ & $22.4 \pm 4.3$ & $18.6 \pm 2.9$ & $27.1 \pm 3.3$ \\
\hline P. ostreatus D1 & $3.5 \pm 1.0$ & $2.0 \pm 0.4$ & $2.5 \pm 0.2$ & $26.1 \pm 1.8$ & $38.2 \pm 5.6$ \\
\hline P. ostreatus LE-BIN 0432 & $21.3 \pm 3.0$ & $27.7 \pm 2.5$ & $32.4 \pm 1.3$ & $28.1 \pm 1.9$ & $37.1 \pm 3.8$ \\
\hline Sch. commune IBPPM 541 & $12.4 \pm 3.4$ & $3.3 \pm 0.3$ & $23.3 \pm 1.4$ & $28.4 \pm 1.9$ & $29.1 \pm 2.3$ \\
\hline St. murashkinskyi LE-BIN 1963 & $42.0 \pm 1.0$ & $27.0 \pm 3.4$ & $38.7 \pm 4.2$ & $19.6 \pm 5.1$ & $21.4 \pm 4.1$ \\
\hline Str. rugosoannulata DSM11372 & $41.8 \pm 1.9$ & $38.7 \pm 11.9$ & $26.9 \pm 3.8$ & $9.8 \pm 3.8$ & $44.3 \pm 12.7$ \\
\hline T. gibbosa LE-BIN 1911 & $17.8 \pm 6.7$ & $6.3 \pm 3.8$ & $2.0 \pm 3.4$ & $0 \pm 0$ & $52.3 \pm 12.1$ \\
\hline T. hirsuta LE-BIN 072 & $34.2 \pm 1.6$ & $59.4 \pm 4.4$ & $21.2 \pm 1.1$ & $60.7 \pm 0.6$ & $35.2 \pm 3.6$ \\
\hline T. maxima LE-BIN 0275 & $38.1 \pm 2.3$ & $49.3 \pm 5.0$ & $35.8 \pm 1.9$ & $40.1 \pm 0.9$ & $42.2 \pm 1.8$ \\
\hline T. ochracea LE-BIN 093 & $22.4 \pm 1.5$ & $6.3 \pm 2.8$ & $0.4 \pm 0.4$ & $0 \pm 0$ & $52.6 \pm 9.3$ \\
\hline T. versicolor DSM11269 & $12.0 \pm 1.9$ & $9.2 \pm 2.2$ & $15.4 \pm 7.5$ & $39.4 \pm 2.3$ & $21.7 \pm 2.8$ \\
\hline T. versicolor MUT 3403 & $1.4 \pm 2.5$ & $11.6 \pm 2.3$ & $2.6 \pm 2.3$ & $19.5 \pm 3.8$ & $29.7 \pm 3.6$ \\
\hline
\end{tabular}

ANT—anthracene, PHEN—phenanthrene, FLU—fluorene; INP—isononylphenol.

In the control treatments (without pollutants), only a trace formation of foam was found; the $\mathrm{E}_{24}$ value does not exceed $1 \%$, and $\mathrm{E}_{48}$ was about $0 \%$. It was found that all studied fungi produced biosurfactants as a response to the presence of hydrophobic pollutants in the culture medium. The emulsifying activity increased from 2 to 70 times. It is shown that the production of emulsifying compounds depends not only on the nature of the pollutant, but also on the strain and species used. For example, from the five studied strains, the highest emulsifying activity was detected in P. ostreatus $\mathrm{f}$. Florida, while the lowest was in P. ostreatus MUT. Among the representatives of the genus Trametes, the most active surfactant producer was T. hirsuta, and the least active was T. gibbosa.

Now, separate reports on the production of biosurfactants by ligninolytic fungi are available. For example, the production of a biosurfactant that increases the solubility of hydrophobic compounds has been found in Coriolus versicolor, Pleurotus ostreatus [22,23,79], Phellinus sp., and Polyporus sulphureus [23], and this biosurfactant was a multicomponent substance consisting of a protein portion and a polysaccharide [22].

The formation of emulsifiers in response to the presence of pollutants in the medium was also found in ascomycetes, among which L. aphanocladii and C. herbarum were the most active. Although the production of biosurfactants by ascomycetes is well-known [80], that 
as a response to the presence of hydrophobic compounds by fungi of genera Fusarium, Cladosporium, and Lecanicillium has not been described previously.

Finally, in our study, the production of emulsifying compounds as a response to the presence in the cultivation medium of hydrophobic pollutants was the common property of wood- and soil-inhabiting basidiomycetes and ascomycetes. Perhaps during the degradation of these substrates, fungus produces substances with emulsifying activity that can make them more accessible. In some cases, the presence of emulsifying activity is associated with the production of EPS, or with "nonpolysaccharide" fungal products, such as glycoproteins [81].

\subsubsection{Extracellular Polysaccharides Production}

The third strategy of adaptation toward the pollutant contamination of the environment can be extracellular polymeric substances such as exopolysaccharides (EPS) production. EPS are produced by both bacteria and fungi. EPS are compounds consisting of a large number of monosaccharides linked glycosidically and can be homo- or heteropolymers of monosaccharide residues and can be linear or branched [82]. For a long time, it has been known that laccases and other lignin-modifying enzymes are embedded within EPS sheets around the hyphae of wood-rotting basidiomycetes, and such structures have been proposed to be involved in recognition mechanisms in fungal cell-wood surface interactions and to play specific roles in the biodeterioration of wood [83]. However, direct effects of fungal EPS on the mode of action of lignin-modifying enzymes have not yet been described in the literature.

In our experiments, EPS concentrations varied from 0.15 to $1.5 \mu \mathrm{g} / \mathrm{mL}$ for all studied fungi. G. candidum, which produced about $3.3 \mu \mathrm{g} / \mathrm{mL}$ of EPS in control treatment (without pollutants), was one exclusion. The decrease in EPS concentration in the presence of all studied pollutants was found for all studied fungi. Its concentration decreased significantly, and in some cases was nearly zero. Simultaneous decrease in EPS concentration and increase of emulsifying activity of cultivation medium in the presence of pollutants should be noted. Perhaps any emulsifying compounds, which fungi produce as a response to the presence of pollutants, can decrease the surface tension of the cultivation medium. This can result in disruptions of the production/synthesis EPS or affect their migration from cell surface to environment. This phenomenon will be studied further.

\section{Conclusions}

Finally, the high degradative activities of the studied fungi toward hazardous pollutants were shown. Table 4 summarizes the properties which we found in the studied fungi. PAHs, oil, and anthraquinone dyes were the most accessible for fungal degradation. The studied surfactants were available for a limited number of fungi. The presence of activities of ligninolytic enzymes correlates with the ability of fungi to degrade pollutants. In addition, most of the studied fungi were able to produce emulsifying compounds, which, apparently, allows them to adapt to the conditions of pollution with hydrophobic pollutants.

The revealed differences depended on the pollutant, the ecological and taxonomic accessory of the fungus, and, in some cases, the fungal strain. The results suggest that fungi with potential development for mycoremediation should be assessed for the following properties: the degradation of the wide range of pollutants without accumulation of the toxic metabolites; the production of emulsifying compounds; the production of ligninolytic enzymes (at least laccase and Mn-peroxidase), which can a necessary condition for the complete degradation of PAH. On the basis of the screening data, such as the degradation of wide range of pollutants without metabolites accumulation, active production of ligninolytic enzymes, and emulsifying compounds, the follow fungi can be chosen as promising for the development of mycoremediation technologies (Table 4): wood-inhabiting basidiomycetes Pleurotus ostreatus f. Florida, Schizophyllum commune, Trametes versicolor MUT 3403, and Trametes versicolor DSM11372; the litter-decomposing basidiomycete Stropharia rugosoannulata, and the ascomycete Cladosporium herbarum. 
Table 4. The main properties of studied fungi.

\begin{tabular}{|c|c|c|c|c|c|c|c|}
\hline \multirow{3}{*}{ Fungi } & \multicolumn{7}{|c|}{ Properties } \\
\hline & \multicolumn{5}{|c|}{ Degradation } & \multirow{2}{*}{$\mathrm{Lac} / \mathrm{MnP} / \mathrm{LiP}$} & \multirow{2}{*}{$\begin{array}{l}\text { Emulsifying } \\
\text { Compounds }\end{array}$} \\
\hline & PAHs & Dyes & Neonol & INP & Oil & & \\
\hline B. adusta MUT 3398 & + & + & + & & & & + \\
\hline C. herbarum MUT 3238 & + & + & & & + & + & + \\
\hline F. oxysporum IBPPM 543 & & + & & & + & & \\
\hline G. candidum MUT4803 & & & + & & & & \\
\hline Lec. aphanocladii IBPPM 542 & + & & & & + & + & \\
\hline Len. betulina LE-BIN 2047 & & + & + & & + & & + \\
\hline P. ostreatus f. Florida IBPPM 540 & + & + & + & & + & + & + \\
\hline P. ostreatus MUT2977 & + & + & & & + & + & \\
\hline P. ostreatus 336 & + & + & & & + & & + \\
\hline P. ostreatus D1 & + & + & & & + & + & \\
\hline P. ostreatus LE-BIN0432 & + & + & & & + & & + \\
\hline Sch. commune IBPPM 541 & + & & & + & + & + & + \\
\hline St. murashkinskyi LE-BIN 1963 & + & & & & + & & + \\
\hline Str. rugosoannulata DSM11372 & + & + & & & + & + & + \\
\hline T. gibbosa LE-BIN 1911 & & + & + & & & & \\
\hline T. hirsuta LE-BIN 072 & & + & & & + & & + \\
\hline T. maxima LE-BIN 0275 & + & + & & & + & & + \\
\hline T. ochracea LE-BIN 093 & & + & & & & & \\
\hline T. versicolor DSM11372 & + & + & & + & + & + & + \\
\hline T. versicolor MUT3403 & + & + & + & & + & + & \\
\hline
\end{tabular}

The most active degraders of this compound include the representatives of the genus Pleurotus, B. adusta, T. versicolor MUT3403, T. gibbosa, and ascomycete G. candidum. P. ostreatus f. Florida and B. adusta more actively removed the oxyethyl chain, and T. versicolor MUT3403 more actively degraded the aromatic ring. Perhaps the fungi, which actively destroyed both parts of the neonol molecule, can be used for more perspective for following studies and practical use.

Supplementary Materials: The following supporting information can be downloaded at: https:// www.mdpi.com/article/10.3390/app12042164/s1, Table S1: List of fungi screened; Figure S1: IRspectra neonol AF9-12: control treatment (blue line) and after P. ostreatus Florida degradation (red line); Figure S2: IR-spectra neonol AF9-12: control treatment (blue line) and after S. rugosoannulata degradation (red line); Figure S3: IR-spectra neonol AF9-12: control treatment (blue line) and after T. versicolor DSM degradation (red line); Figure S4: IR-spectra Isononylphenol: control treatment (green line) and after Sch. commune degradation (1 week-blue and 2 weeks-red lines)

Author Contributions: Conceptualization, N.P., O.T.; methodology, N.P., E.D., V.G. and E.S.; validation, N.P., E.D.; investigation, N.P., E.D., S.K., E.S., V.G., S.G., E.K.; writing-original draft preparation, N.P.; writing-review and editing N.P., D.S., G.C.V. and O.T.; supervision, O.T.; funding acquisition, O.T. All authors have read and agreed to the published version of the manuscript.

Funding: This study was funded by the Russian Science Foundation (grant number 16-14-00081). A part of this work was further supported by the Helmholtz-Association of German Research Centres.

Institutional Review Board Statement: Not applicable. 
Informed Consent Statement: Not applicable.

Data Availability Statement: Not applicable.

Acknowledgments: This research was carried out under research theme no. 121031700141-7 and in part of degradation experiments supported by a grant from the Russian Science Foundation (project no. 16-14-00081). A part of this work was supported by the Helmholtz-Association of German Research Centres in the frame of the Integration Platform "Tapping nature's potential for sustainable production and a healthy environment" at the UFZ. We thank V.E. Nikitina (IBPPM RAS) and O.V. Koroleva (Federal Research Centre "Fundamentals of Biotechnology" RAS) for kindly providing us with fungal strains. Compliance with ethical standards.

Conflicts of Interest: The authors declare that they have no conflicts of interest.

Ethical Approval: This article does not contain any studies with human participants or animals performed by any of the authors.

\section{Abbreviations}

PAHs polycyclic aromatic hydrocarbons

ABTS 2,2'-azino-bis(3-ethylbenzothiazoline-6-sulfonic acid)diammonium salt

DMP 2,6-dimethoxyphenol

\section{References}

1. Harms, H.; Schlosser, D.; Wick, L.Y. Untapped potential: Exploiting fungi in bioremediation of hazardous chemicals. Nat. Rev. Microbiol. 2011, 9, 177-192. [CrossRef]

2. Treu, R.; Falandysz, J. Mycoremediation of hydrocarbons with basidiomycetes-A review. J. Environ. Sci. Health Part B 2017, 52, 148-155. [CrossRef] [PubMed]

3. Cecchi, G.; Vagge, G.; Cutroneo, L.; Greco, G.; Di Piazza, S.; Faga, M.; Zotti, M.; Capello, M. Fungi as potential tool for polluted port sediment remediation. Environ. Sci. Pollut. Res. 2019, 26, 35602-35609. [CrossRef] [PubMed]

4. Noman, E.; Al-Gheethi, A.; Mohamed, R.M.S.R.; Atalip, B. Myco-Remediation of Xenobiotic Organic Compounds for a Sustainable Environment: A Critical Review. Top. Curr. Chem. 2019, 377, 17. [CrossRef] [PubMed]

5. Akhtar, N.; Mannan, M.A.-U. Mycoremediation: Expunging environmental pollutants. Biotechnol. Rep. 2020, 26, e00452. [CrossRef] [PubMed]

6. Kumar, A.; Yadav, A.N.; Mondal, R.; Kour, D.; Subrahmanyam, G.; Shabnam, A.A.; Khan, S.A.; Yadav, K.K.; Sharma, G.K.; Cabral-Pinto, M.; et al. Myco-remediation: A mechanistic understanding of contaminants alleviation from natural environment and future prospect. Chemosphere 2021, 284, 131325. [CrossRef]

7. Wong, D.W.S. Structure and Action Mechanism of Ligninolytic Enzymes. Appl. Biochem. Biotechnol. 2009, 157, 174-209. [CrossRef]

8. Pozdnyakova, N.N. Involvement of the Ligninolytic System of White-Rot and Litter-Decomposing Fungi in the Degradation of Polycyclic Aromatic Hydrocarbons. Biotechnol. Res. Int. 2012, 2012, 1-20. [CrossRef]

9. Wang, X.; Yao, B.; Su, X. Linking Enzymatic Oxidative Degradation of Lignin to Organics Detoxification. Int. J. Mol. Sci. 2018, 19, 3373. [CrossRef]

10. Yateem, A.; Balba, M.; Al-Awadhi, N.; El-Nawawy, A. White rot fungi and their role in remediating oil-contaminated soil. Environ. Int. 1998, 24, 181-187. [CrossRef]

11. Ishikhuemhen, O.; Anoliefo, G.; Oghale, O. Bioremediation of crude oil polluted soil by the white rot fungus Pleurotus tuberreqium (Fr.) Sing. Environ. Sci. Pollut. Res. 2003, 10, 108-112. [CrossRef] [PubMed]

12. Ogbo, E.; Okhuoya, J. Biodegradation of aliphatic, aromatic, resinic and asphaltic fractions of crude oil contaminated soils by Pleurotus tuber-regium Fr. Singer-A white rot fungus. Afr. J. Biotechnol. 2008, 4, 4291-4297.

13. Okerentugba, P.O.; Orji, F.; Ibiene, A.A.; Elemo, G.N. Spend mushroom compost for bioremediation of petroleum hydrocarbon polluted soil: A review. Glob. Adv. Res. J. Environ. Sci. Toxicol. 2015, 4, 001-007.

14. Mohammadi-Sichani, M.M.; Assadi, M.M.; Farazmand, A.; Kianirad, M.; Ahadi, A.M.; Ghahderijani, H.H. Bioremediation of soil contaminated crude oil by Agaricomycetes. J. Environ. Health Sci. Eng. 2017, 15, 8. [CrossRef] [PubMed]

15. Abdel-Shafy, H.I.; Mansour, M.S.M. A review on polycyclic aromatic hydrocarbons: Source, environmental impact, effect on human health and remediation. Egypt. J. Pet. 2016, 25, 107-123. [CrossRef]

16. Grasso, D.; Subramaniam, K.; Pignatello, J.; Yang, Y.; Ratté, D. Micellar desorption of polynuclear aromatic hydrocarbons from contaminated soil. Colloids Surf. A Physicochem. Eng. Asp. 2001, 194, 65-74. [CrossRef]

17. Sartoros, C.; Yerushalmi, L.; Béron, P.; Guiot, S.R. Effects of surfactant and temperature on biotransformation kinetics of anthracene and pyrene. Chemosphere 2005, 61, 1042-1050. [CrossRef]

18. Ying, G.-G.; Williams, B.; Kookana, R. Environmental fate of alkylphenols and alkylphenol ethoxylates-A review. Environ. Int. 2002, 28, 215-226. [CrossRef] 
19. Subramanian, V.; Yadav, J.S. Role of P450 Monooxygenases in the Degradation of the Endocrine-Disrupting Chemical Nonylphenol by the White Rot Fungus Phanerochaete chrysosporium. Appl. Environ. Microbiol. 2009, 75, 5570-5580. [CrossRef]

20. Baboshin, M.A.; Golovleva, L.A. Aerobic bacterial degradation of polycyclic aromatic hydrocarbons (PAHs) and its kinetic aspects. Microbiology 2012, 81, 639-650. [CrossRef]

21. Song, H.-G. Comparison of pyrene biodegradation by white rot fungi. World J. Microbiol. Biotechnol. 1999, 15, 669-672. [CrossRef]

22. Arun, A.; Raja, P.P.; Arthi, R.; Ananthi, M.; Kumar, K.S.; Eyini, M. Polycyclic aromatic hydrocarbons (PAHs) biodegradation by basidiomycetes fungi, pseudomonas isolate, and their cocultures: Comparative in vivo and in silico approach. Appl. Biochem. Biotechnol. 2008, 151, 132-142. [CrossRef] [PubMed]

23. Arun, A.; Eyini, M. Comparative studies on lignin and polycyclic aromatic hydrocarbons degradation by basidiomycetes fungi. Bioresour. Technol. 2011, 102, 8063-8070. [CrossRef] [PubMed]

24. Garcia-Delgado, C.; Alfaro-Barta, I.; Eymar, У. Combination of biochar amendment and mycoremediation for polycyclic aromatic hydrocarbons immobilization and biodegradation in creosote-contaminated soil. J. Hazard. Mater. 2015, 285, 259-266. [CrossRef]

25. Bezalel, L.; Hadar, Y.; Cerniglia, C.E. Enzymatic Mechanisms involved in phenanthrene degradation by the white rot fungus Pleurotus ostreatus. Appl. Environ. Microbiol. 1997, 63, 2495-2501. [CrossRef]

26. Kirk, T.; Croan, S.; Tien, M.; Murtagh, K.E.; Farrell, R.L. Production of multiple ligninases by Phanerochaete chrysosporium: Effect of selected growth conditions and use of a mutant strain. Enzym. Microb. Technol. 1986, 8, 27-32. [CrossRef]

27. Polunina, A.G.; Kushik, G.I. Metody analiza organicheskogo veshchestva porod, nefti i gaza (Methods of Analyslis of Organic Matter in Rocks, Oil, and Gas). Tyumen' Tr. Zap.-Sib. NIGNI 1977, 122, 6-7. (In Russian)

28. Klimenko, N.A.; Panchenko, N.P. Opredelenie nPAV v stochnih vodah (Determination of non-ionic surfactants in waster waters). Text. Ind. 1971, 2, 85-86. (In Russian)

29. Wang, P.; Nong, X.-H.; Ge, J.-H. Aerobic biodegradation of nonylphenol ethoxylates in shaking-flask test. Electron. J. Biotechnol. 2011, 14, 1. [CrossRef]

30. Pozdnyakova, N.N.; Jarosz-Wilkolazka, A.; Polak, J.; Graz, M.; Turkovskaya, O.V. Decolourisation of anthraquinone-and anthracene-type dyes by versatile peroxidases from Bjerkandera fumosa and Pleurotus ostreatus D1. Biocatal. Biotransform. 2015, 33, 69-80. [CrossRef]

31. Niku-Paavola, M.; Karhunen, E.; Salola, P.; Raunio, V. Ligninolytic enzymes of the white rot fungus Phlebia radiate. Biochem. J. 1988, 254, 877-884. [CrossRef] [PubMed]

32. Heinfling, A.; Martinez, M.; Martinez, A.; Bergbauer, M.; Szewzyk, U. Purification and characterization of peroxidases from dye-decolorizing fungus Bjerkandera adusta. FEMS Microbiol. Lett. 1998, 16, 543-550.

33. Tien, M.; Kirk, K. Lignin-degrading enzyme from Phanerochaete chrysosporium: Purification, characterization, and catalytic properties of a unique H2O2-requiring oxygenase. Proc. Nat. Acad. Sci. USA 1984, 81, 2280-2284. [CrossRef]

34. Cooper, D.G.; Goldenberg, B.G. Surface-Active Agents from Two Bacillus Species. Appl. Environ. Microbiol. 1987, 53, 224-229. [CrossRef] [PubMed]

35. Bailey, J.B. A note on the use of dinitrosalicylic acid for determining the products of enzymatic reactions. Appl. Microbiol. Biotechnol. 1988, 29, 494-496. [CrossRef]

36. DuBois, M.; Gilles, K.A.; Hamilton, J.K.; Rebers, P.A.; Smith, F. Colorimetric method for determination of sugars and related substances. Anal. Chem. 1956, 28, 350-356. [CrossRef]

37. Zeng, J.; Lin, X.; Zhang, J.; Zhu, H.; Chen, H.; Wong, M.H. Successive transformation of benzo[a]pyrene by laccase of Trametes versicolor and pyrene-degrading Mycobacterium strains. Appl. Microbiol. Biotechnol. 2012, 97, 3183-3194. [CrossRef]

38. Kadri, T.; Rouissi, T.; Brar, S.K.; Cledon, M.; Sarma, S.; Verma, M. Biodegradation of polycyclic aromatic hydrocarbons (PAHs) by fungal enzymes: A review. J. Environ. Sci. 2017, 51, 52-74. [CrossRef]

39. Steffen, K.T.; Schubert, S.; Tuomela, M.; Hatakka, A.; Hofrichter, M. Enhancement of bioconversion of high-molecular mass polycyclic aromatic hydrocarbons in contaminated non-sterile soil by litter-decomposing fungi. Biodegradation 2006, 18, 359-369. [CrossRef]

40. Kabiersch, G.; Rajasärkkä, J.; Ullrich, R.; Tuomela, M.; Hofrichter, M.; Virta, M.; Hatakka, A.; Steffen, K. Fate of bisphenol A during treatment with the litter-decomposing fungi Stropharia rugosoannulata and Stropharia coronilla. Chemosphere 2011, 83, 226-232. [CrossRef]

41. Fariba, M.; Simin, N.; Alireza, M.; Ramin, N.; Doustmorad, Z.; Gholam, K.; Abdolkarim, C. Phytoremediation of petroleumpolluted soils: Application of Polygonum aviculare and its root-associated (penetrated) fungal strains for bioremediation of petroleum-polluted soils. Ecotoxicol. Environ. Saf. 2010, 73, 613-619.

42. Jacques, R.J.; Okeke, B.C.; Bento, F.M.; Teixeira, A.S.; Peralba, M.C.; Camargo, F.A. Microbial consortium bioaugmentation of a polycyclic aromatic hydrocarbons contaminated soil. Bioresour. Technol. 2008, 99, 2637-2643. [CrossRef] [PubMed]

43. Kim, S.J.; Ishikawa, K.; Hirai, M.; Shoda, M. Characteristics of a newly isolated fungus, Geotrichum candidum Dec 1 , which decolorizes various dyes. J. Ferment. Bioeng. 1995, 79, 601-607. [CrossRef]

44. Potin, O.; Veignie, E.; Rafin, C. Biodegradation of polycyclic aromatic hydrocarbons (PAHs) by Cladosporium sphaerospermum isolated from an aged PAH contaminated soil. FEMS Microbiol. Ecol. 2004, 51, 71-78. [CrossRef] [PubMed]

45. Pinto, A.; Serrano, C.; Pires, T.; Mestrinho, E.; Dias, L.; Teixeira, D.M.; Caldeira, A.T. Degradation of terbuthylazine, difenoconazole and pendimethalin pesticides by selected fungi cultures. Sci. Total Environ. 2012, 435-436, 402-410. [CrossRef] [PubMed] 
46. Vroumsia, T.; Steiman, R.; Seigle-Murandi, F.; Benoit-Guyod, J.-L. Effects of culture parameters on the degradation of 2,4dichlorophenoxyacetic acid (2,4-D) and 2,4-dichlorophenol (2,4-DCP) by selected fungi. Chemosphere 1999, 39, 1397-1405. [CrossRef]

47. Krivobok, S.; Miriouchkine, E.; Seigle-Murandi, F.; Benoit-Guyod, J.-L. Biodegradation of Anthracene by soil fungi. Chemosphere 1998, 37, 523-530. [CrossRef]

48. Pozdnyakova, N.N.; Varese, G.C.; Prigione, V.; Dubrovskaya, E.V.; Balandina, S.A.; Turkovskaya, O.V. Degradative properties of two newly isolated strains of the ascomycetes Fusarium oxysporum and Lecanicillium aphanocladii. Int. Microbiol. 2019, 22, 103-110. [CrossRef]

49. Ghosal, D.; Ghosh, S.; Dutta, T.K.; Ahn, Y. Current State of Knowledge in Microbial Degradation of Polycyclic Aromatic Hydrocarbons (PAHs): A Review. Front. Microbiol. 2016, 7, 1369. [CrossRef]

50. Gramss, G.; Mascher, K. Mutual influence of soil basidiomycetes and white mustard plants on their enzymatic and catabolic activities. J. Basic Microbiol. 2011, 51, 40-51. [CrossRef]

51. Hammel, K.; Green, B.; Gai, W.Z. Ring fission of anthracene by a eukaryote. Proc. Natl. Acad. Sci. USA 1991, 88, 10605-10608. [CrossRef] [PubMed]

52. Xu, M.; Guo, J.; Zeng, G.; Zhong, X.; Sun, G. Decolourization of anthraquinone dye by Shewanella decolorationis S12. Appl. Microbiol. Biotechnol. 2006, 71, 246-251. [CrossRef] [PubMed]

53. Eichlerová, I.; Homolka, L.; Benada, O.; Kofroňová, O.; Hubálek, T.; Nerud, F. Decolorization of Orange G and Remazol Brilliant Blue $\mathrm{R}$ by the white rot fungus Dichomitus squalens: Toxicological evaluation and morphological study. Chemosphere 2007, 69, 795-802. [CrossRef] [PubMed]

54. Sugano, Y.; Matsushima, Y.; Shoda, M. Complete decolourization of the anthraquinone dye Reactive blue 5 by the concerted action of two peroxidases from Thanatephorus cucumeris Dec1. Appl. Microbiol. Biotechnol. 2006, 73, 862-871. [CrossRef] [PubMed]

55. Husain, Q. Peroxidase mediated decolourization and remediation of wastewater containing industrial dyes: A review. Rev. Environ. Sci. Biotechnol. 2010, 9, 117-140. [CrossRef]

56. Liu, W.; Chao, Y.; Yang, X.; Bao, H.; Qian, S. Biodecolourization of azo, anthraquinonic and triphenylmethane dyes by white rot fungi and laccase-secreting engineered strain. J. Ind. Microbiol. Biotechnol. 2004, 31, 127-132. [CrossRef]

57. Ogbo, E.; Tabuanu, A.; Ubebe, R. Phytotoxicity assay of diesel fuel-spiked substrates remediated with Pleurotus tuber-regium using Zea mays. Int. J. Appl. Res. Nat. Prod. 2010, 3, 12-16.

58. Bovio, E.; Gnavi, G.; Prigione, V.; Spina, F.; Denaro, R.; Yakimov, M.; Calogero, R.; Crisafi, F.; Varese, G.C. The culturable mycobiota of a Mediterranean marine site after an oil spill: Isolation, identification and potential application in bioremediation. Sci. Total Environ. 2017, 576, 310-318. [CrossRef]

59. Márquez-Rocha, F.J.; Hernández-Rodríguez, V.Z.; Vazquez-Duhalt, R. Biodegradation of soil-adsorbed polycyclic aromatic hydrocarbons by the white rot fungus Pleurotus ostreatus. Biotechnol. Lett. 2000, 22, 469-472. [CrossRef]

60. Bhattacharaya, S.; Angayarkanni, J.; Das, A.; Palaniswamy, M. Mycoremediation of benzo[a]pyrene by Pleurotus ostreatus isolated from Wayanad district in Kerala, India. Int. J. Pharm. Bio. Sci. 2012, 2, 84-93.

61. Zheng, Z.; Obbard, J.P. Polycyclic Aromatic Hydrocarbon Removal from Soil by Surfactant Solubilization and Phanerochaete chrysosporium Oxidation. J. Environ. Qual. 2002, 31, 1842-1847. [CrossRef] [PubMed]

62. Moon, D.-S.; Song, H.-G. Degradation of Alkylphenols by White Rot Fungus Irpex lacteus and Its Manganese Peroxidase. Appl. Biochem. Biotechnol. 2012, 168, 542-549. [CrossRef] [PubMed]

63. Zakupra, V.A. Methods of analysis and control in the production of surface-active substances. M. Chem. 1977, 368. (In Russian)

64. Perov, P.A.; Glukhova, L.Y.; Markova, E.I.; Kudasova, E.I.; Chernih, V.A. IR, NMR and Raman Spectra of Surfactants, Raw Materials and Preparations Based on Them: Catalog.; TsNIITEneftekhim: Moscow, Russia, 1989; p. 233. (In Russian)

65. Nakanishi, K. Infrared spectra and structure of organic compounds/K. Nakanishi. Per. English. M. Mir 1965, 216. (In Russian)

66. Shipman, L. Ab Initio Quantum Mechanical Characterization of the Ground Electronic State of Benzo[a]pyrene. Implications for the Mechanism of Polynuclear Aromatic Hydrocarbon Oxidation to Epoxides by Cytochrome P450, Polynuclear Aromatic Hydrocarbons; Jones, P., Leber, P., Eds.; Michigan: Ann Arbor Science: Ann Arbor, MI, USA, 1979; Volume 3, pp. 139-143.

67. Cerniglia, C. Microbial metabolism of polycyclic aromatic hydrocarbons. Adv. Appl. Microbiol. 1984, 30, 31-71.

68. McConkey, B.J.; Duxbury, C.L.; Dixon, D.G.; Greenberg, B.M. Toxicity of a pah photooxidation product to the bacteria photobacterium phosphoreum and the duckweed lemna gibba: Effects of phenanthrene and its primary photoproduct, phenanthrenequinone. Environ. Toxicol. Chem. 1997, 16, 892-899. [CrossRef]

69. Baboshin, M.A.; Baskunov, B.P.; Finkel'shtein, Z.I.; Golovlev, E.L.; Golovleva, L.A. Microbial transformation of antracene and phenanthrene. Microbiol. Mosc. 2005, 74, 303-309. [CrossRef]

70. Muratova, A.; Pozdnyakova, N.; Makarov, O.; Baboshin, M.; Baskunov, B.; Myasoedova, N.; Golovleva, L.; Turkovskaya, O. Degradation of phenanthrene by the rhizobacterium Ensifer meliloti. Biodegradation 2014, 25, 787-795. [CrossRef]

71. Kireeva, N.A.; Kuzyakhmetov, G.G.; Miftakhova, A.M.; Vodop'yanov, V.V. Fitotoksichnost' antropogenno zagryaznennykh pochv (Phytotoxicity of Anthropogenically Contaminated Soils). Ufa Gilem 2003, 113. (In Russian)

72. Šašek, V.; Cajthaml, T.; Bhatt, M. Use of fungal technology in soil remediation: A Case Study. Water Air Soil Pollut. Focus 2003, 3, 5-14. [CrossRef] 
73. Muratova, A.; Pozdnyakova, N.; Golubev, S.; Wittenmayer, L.; Makarov, O.; Merbach, W.; Turkovskaya, O. Oxidoreductase activity of sorghum root exudates in a phenanthrene-contaminated environment. Chemosphere 2009, 74, 1031-1036. [CrossRef] [PubMed]

74. Kim, S.J.; Shoda, M. Purification and Characterization of a Novel Peroxidase from Geotrichum candidum Dec 1 Involved in Decolorization of Dyes. Appl. Environ. Microbiol. 1999, 65, 1029-1035. [CrossRef]

75. Cajthaml, T. Biodegradation of endocrine-disrupting compounds by ligninolytic fungi: Mechanisms involved in the degradation. Environ. Microbiol. 2015, 17, 4822-4834. [CrossRef] [PubMed]

76. Pozdnyakova, N.N.; Nikiforova, S.V.; Makarov, O.E.; Chernyshova, M.P.; Pankin, K.E.; Turkovskaya, O.V. Influence of cultivation conditions on pyrene degradation by the fungus Pleurotus Ostreatus D1. World J. Microbiol. Biotechnol. 2009, 26, 205-211. [CrossRef]

77. Pozdnyakova, N.; Dubrovskaya, E.; Chernyshova, M.; Makarov, O.; Golubev, S.; Balandina, S.; Turkovskaya, O. The degradation of three-ringed polycyclic aromatic hydrocarbons by wood-inhabiting fungus Pleurotus ostreatus and soil-inhabiting fungus Agaricus bisporus. Fungal Biol. 2018, 122, 363-372. [CrossRef]

78. Pozdnyakova, N.N.; Chernyshova, M.; Grinev, V.S.; Landesman, E.O.; Koroleva, O.V.; Turkovskaya, O.V. Degradation of fluorene and fluoranthene by the basidiomycete Pleurotus ostreatus. Appl. Biochem. Microbiol. 2016, 52, 621-628. [CrossRef]

79. Nikiforova, S.V.; Pozdnyakova, N.N.; Turkovskaya, O.V. Emulsifying Agent Production During PAHs Degradation by the White Rot Fungus Pleurotus Ostreatus D1. Curr. Microbiol. 2009, 58, 554-558. [CrossRef]

80. Bhardwaj, S.S.C.A.H.K.C.G. Biosurfactants from Fungi: A Review. J. Pet. Environ. Biotechnol. 2013, 4, 1-6. [CrossRef]

81. Veignie, E.; Vinogradov, E.; Sadovskaya, I.; Coulon, C.; Rafin, C. Preliminary Characterizations of a Carbohydrate from the Concentrated Culture Filtrate from Fusarium solani and Its Role in Benzo[a]Pyrene Solubilization. Adv. Microbiol. 2012, 2, 375-381. [CrossRef]

82. Seviour, R.J.; McNeil, B.; Fazenda, M.; Harvey, L.M. Operating bioreactors for microbial exopolysaccharide production. Crit. Rev. Biotechnol. 2010, 31, 170-185. [CrossRef]

83. Gutiérrez, A.; Martínez, M.; Almendros, G.; Gonzalez-Vila, F.J.; Martínez, A.T. Hyphal-sheath polysaccharides in fungal deterioration. Sci. Total Environ. 1995, 167, 315-328. [CrossRef] 